Review

\title{
Mitochondrial membrane lipid remodeling in pathophysiology: A new target for diet and therapeutic interventions
}

\author{
João P. Monteiro ${ }^{\mathrm{a}, \mathrm{b}}$, Paulo J. Oliveira ${ }^{\mathrm{a}, 1}$, Amália S. Jurado ${ }^{\mathrm{a}, \mathrm{b}, *, 1}$ \\ ${ }^{a}$ CNC - Center for Neuroscience and Cell Biology, University of Coimbra, Portugal \\ ${ }^{\mathrm{b}}$ Department of Life Sciences, University of Coimbra, Portugal
}

\section{A R T I C L E I N F O}

\section{Article history:}

Received 1 March 2013

Received in revised form 14 June 2013

Accepted 17 June 2013

Available online 1 July 2013

\section{Keywords:}

Mitochondrial membrane lipids

Cardiolipin

Apoptosis

Aging

Pathology

\begin{abstract}
A B S T R A C T
Mitochondria are arbiters in the fragile balance between cell life and death. These organelles present an intricate membrane system, with a peculiar lipid composition and displaying transverse as well as lateral asymmetry. Some lipids are synthesized inside mitochondria, while others have to be imported or acquired in the form of precursors. Here, we review different processes, including external interventions (e.g., diet) and a range of biological events (apoptosis, disease and aging), which may result in alterations of mitochondrial membrane lipid content. Cardiolipin, the mitochondria lipid trademark, whose biosynthetic pathway is highly regulated, will deserve special attention in this review. The modulation of mitochondrial membrane lipid composition, especially by diet, as a therapeutic strategy for the treatment of some pathologies will be also addressed.
\end{abstract}

(c) 2013 Elsevier Ltd. All rights reserved.

\section{Contents}

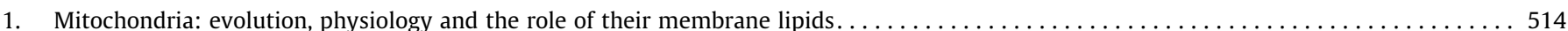

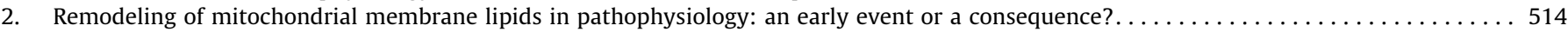

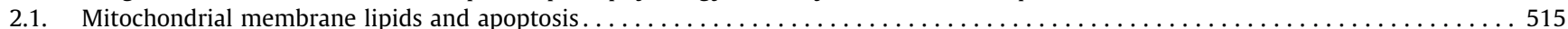

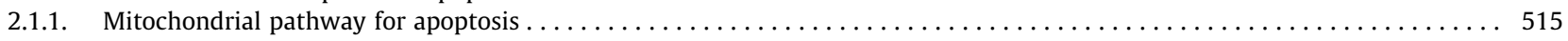

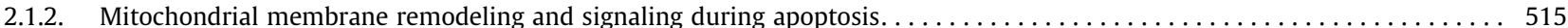

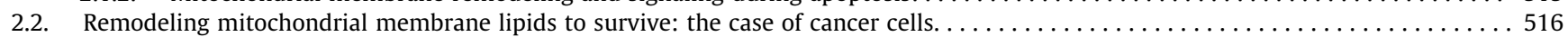

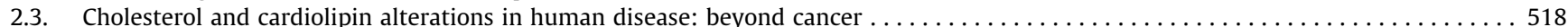

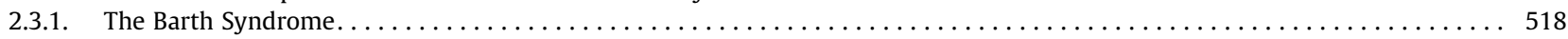

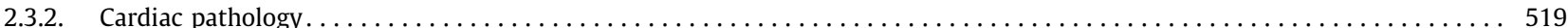

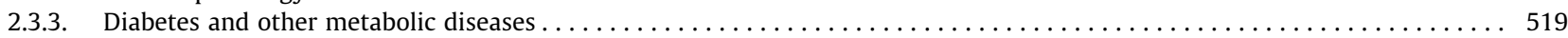

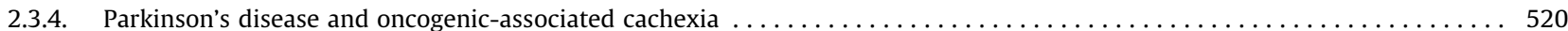

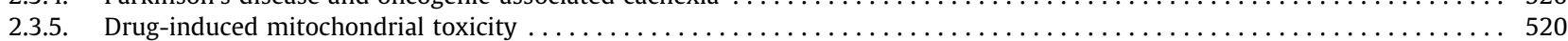

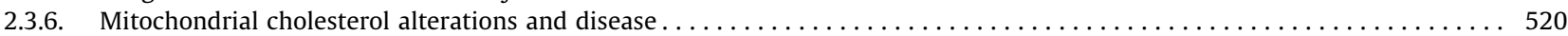

Abbreviations: AIF, apoptosis-inducing factor; ATP, adenosine triphosphate; BTHS, Barth syndrome; CL, cardiolipin; cyt c, cytochrome $c$; DNA, deoxyribonucleic acid; DOX, doxorubicin; ER, endoplasmic reticulum; GD3, ganglioside GD3; IMM, inner mitochondrial membrane; iPLA2 $\gamma$, calcium-independent phospholipase A2 $\gamma$; MAM, mitochondria-associated membrane; MLCL, monolysocardiolipin; MPT, mitochondrial permeability transition; mtDNA, mitochondrial DNA; OMM, outer mitochondrial membrane; PC, phosphatidylcholine; PE, phosphatidylethanolamine; PI, phosphatidylinositol; PG, phosphatidylglycerol; PS, phosphatidylserine; PTP, mitochondrial permeability transition pore; PUFA, polyunsaturated fatty acid; ROS, reactive oxygen species; Smac/DIABLO, second mitochondria-derived activator of caspases/direct IAP binding protein with low Pi; UCP, uncoupling protein.

* Corresponding author. Address: CNC-Center for Neuroscience and Cell Biology, Department of Life Sciences, University of Coimbra, Apartado 3046, 3001-401 Coimbra, Portugal. Tel.: +351239 853600; fax: +351239853409.

E-mail address: asjurado@bioq.uc.pt (A.S. Jurado).

1 Both authors share senior authorship. 
2.4. Mitochondrial membrane lipid composition changes in aging $\ldots \ldots \ldots \ldots$

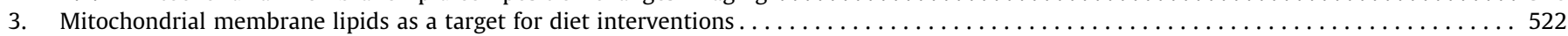

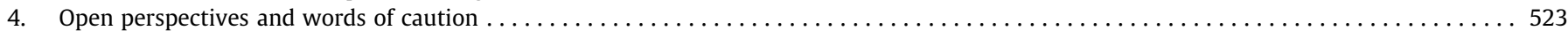

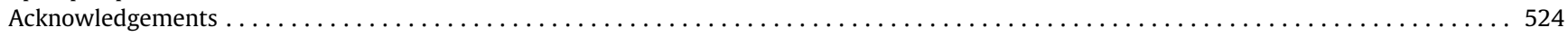

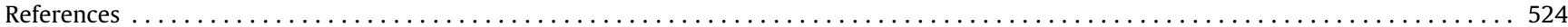

\section{Mitochondria: evolution, physiology and the role of their membrane lipids}

Mitochondria are membrane-enclosed cellular structures, which are classically defined as energy-producing organelles, although their influence extends to many other cell functions. In the classic, although controversial at the time, endosymbiotic theory proposed by Lynn Margulis in the late sixties [1], an amitochondriate anaerobic eukaryote engulfed an oxygen consuming proteobacterium. In one of those chance events that most likely allowed for the expansion of life on Earth, the engulfed bacterium was not destroyed, but rather lived in symbiosis with its host. The emergent biological system became equipped with skills to adapt to different types of environment, especially oxygen-rich niches. In fact, this new aerobic organism, an ancestor of eukaryotic cells, earned the advantage of using a wider variety of substrates to generate even higher amounts of energy, which provided it with a replicative superiority in relation to competition [2]. By its turn, the proteobacterium gained a better protection from the harshness of the environment and a steady flux of substrates. Over millions of years, the proteobacterium evolved into what we now recognize as the mitochondrion. Further evolution steps resulted in a remodeling of mitochondria to suit the needs of fungi, animals or plants. Thus, despite being mostly similar to their mammalian counterparts, plant mitochondria have interesting differentiating features [3], including inner membrane alternative oxidases (AOX) [4] and type II NAD(P)H dehydrogenases [5], which result in high metabolic plasticity and make plants endowed with a remarkable potential for adaptation. Interestingly, taking into account the widespread taxonomic distribution of AOX, which is also present in prokaryotes and, among eukaryotes, in fungi, plants and animals, it has been proposed that the proteobacterial ancestor from which mitochondria evolved were provided with AOX and this had been lost over evolutionary time by vertebrates and arthropods [6].

Mitochondrial bioenergetics depends largely on the physiology of the inner mitochondrial membrane (IMM), which hosts the redox complexes of the respiratory system and phosphorylation apparatus that performs the highly efficient energy-generating process known as oxidative phosphorylation. In this process, the energy made available from the oxidation of nutrients is used to drive ATP synthesis. Electrons from specific substrates, funneled to nicotinamide nucleotides $\left(\mathrm{NAD}^{+}\right.$or $\mathrm{NADP}^{+}$) or flavin nucleotides (FMN or FAD), enter the mitochondrial electron transport chain, through which they are transferred to oxygen [7]. As electrons flow through a sequence of membrane-bound protein and non-protein carriers, protons are pumped from the mitochondrial matrix to the intermembrane space. Therefore, according to the chemiosmotic theory introduced by Peter Mitchell [8], the free energy of substrate oxidation is conserved as a transmembrane proton electrochemical potential $(\Delta \mathrm{p})$, part of which composed by the electric component $(\Delta \Psi)$ which is used to drive ATP synthesis by the ATP synthase complex, through a rotational catalysis mechanism [9]. Mitochondrial oxidative phosphorylation accounts for about $90 \%$ of cellular oxygen consumption and provides more than $80 \%$ of the energy demands for cellular life metabolism [10]. However, besides cellular energy production, mitochondrial have other functions in the cell, including the modulation of calcium signaling, regulation of cell death, the maintenance of cellular redox balance and the housing of important biosynthetic pathways [11]. Therefore, it is fair to say that mitochondria function as gatekeepers of cell life and cell death. In the latter case, mitochondria have been associated with both apoptotic and necrotic cell death [11], discussed in detail in the next section.

Mitochondrial membrane lipids are involved in a number of processes as diverse as protein biogenesis, energy production, membrane fusion and apoptosis [12]. Moreover, spatially defined lipid distribution (Fig. 1A) may also affect mitochondrial processes as fusion and fission or the topology of proteins in the membrane plane [12]. In the particular case of energy production, evidence that membrane lipids modulate mitochondrial respiration has been generated by dietary manipulations of the lipid content in mitochondrial membranes. These approaches have shown that dietary interventions that are able to influence mitochondrial membrane lipid composition, hence modifying its physical properties [13-20], alter respiration [20-29] as well as other mitochondrial processes involving generation of reactive oxygen species (ROS) [30] and $\mathrm{Ca}^{2+}$-induced MPT [20,31]. The role of membrane lipids in mitochondria function is best exemplified by cardiolipin (CL), the signature phospholipid of those organelles. CL has been linked to a number of important mitochondrial processes, including oxidative phosphorylation [32], apoptosis [33] and the assembly and function of mitochondrial membrane proteins [34].

The phospholipid composition of mitochondrial membranes is thought to be under genetic control, and varies markedly between different tissues and organs within an individual animal, representing a specific feature of each membrane [35].

Under physiologic conditions, phospholipid composition of mitochondria relies on the conjugated expression and activity of a number of proteins involved in lipid synthesis and interconversion. Mitochondrial regulation of phospholipid levels is not fully understood, but it depends on the action of mitochondrial proteins, as reported for CL and PE [36]. On the other hand, studies on genetic manipulation of mitochondria membrane lipid content [37-39] point to the need to maintain a "physiologic" lipid composition of mitochondria membranes. We envision that environmental factors, including diet, can impact the genetic control of lipid synthesis, remodeling and incorporation in membranes, thus inducing alterations in membrane lipid composition. Despite diet-induced changes in the expression/genetic regulation of mitochondrial proteins have been reported $[40,41]$, the mechanisms involved in the regulation of mitochondrial lipid content and their susceptibility to the interference of external stressors at the level of gene/protein expression were not yet fully clarified. An alternative way for external interventions to alter mitochondrial membrane lipid composition may be related with the supply of different lipid precursors, which may be in excess or not available for lipid synthesis.

In the following sections, we will address issues regarding the modulation of mitochondrial membrane lipid composition in the context of apoptosis, cancer or other diseases and aging (Section 2), as well as the possibility to explore diet-induced alterations in mitochondrial membrane lipids as a strategy for therapeutic purposes (Section 3).

\section{Remodeling of mitochondrial membrane lipids in pathophysiology: an early event or a consequence?}

A great deal of data has been accumulated regarding alterations of cell and organellar lipids in health and disease conditions. An 
(A)

(B)

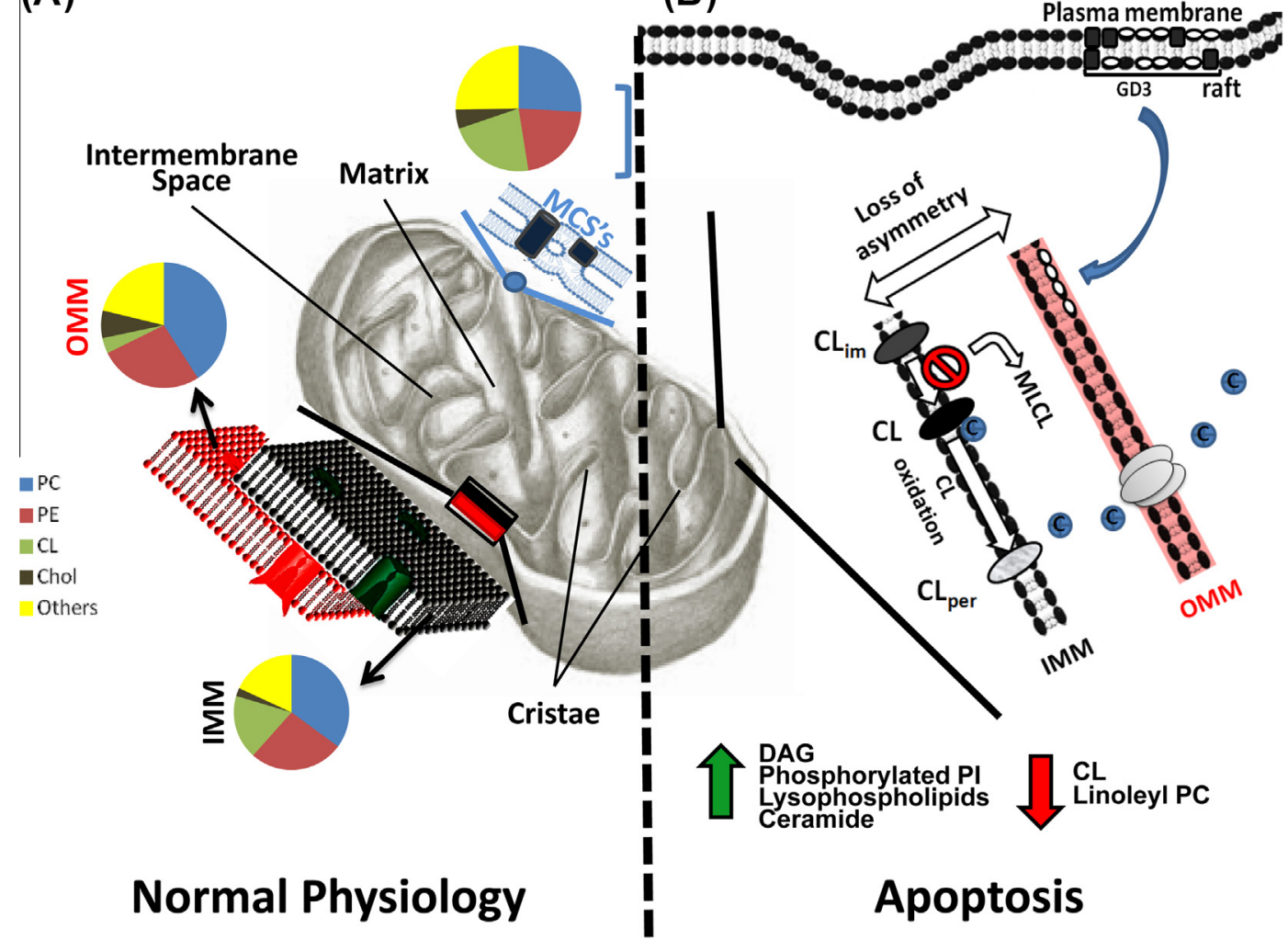

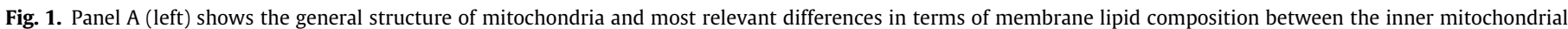

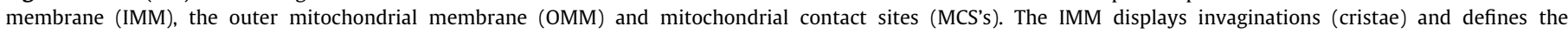

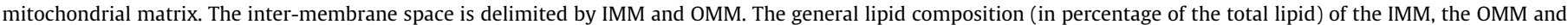

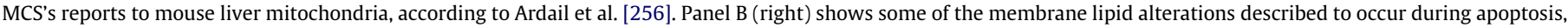

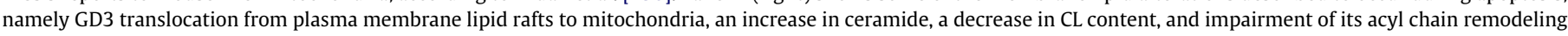

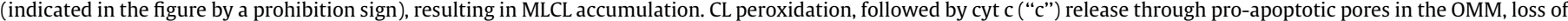

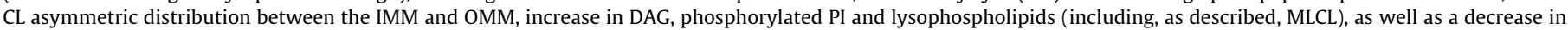
linoleyl PC were also reported as taking place during apoptosis. $\mathrm{CL}_{\mathrm{im}}$ : immature $\mathrm{CL} ; \mathrm{MLCL}$ : monolyso $\mathrm{CL}$; $\mathrm{CL}_{\mathrm{per}}$ : peroxidized $\mathrm{CL}$.

important question is why membrane lipids are altered. This is an issue to be solved by functional lipidomics, which focuses on unraveling the molecular mechanisms that trigger (upstream events) and are triggered by (downstream events) membrane lipid alterations. Therefore, the major challenge for lipidomic research is to find out how membrane lipid changes are associated to known or unknown cell signaling pathways. In this section, alterations of mitochondria membrane lipids related to apoptosis, cancer or other diseases and aging are reviewed, and a mechanistic perspective is provided whenever sufficient data are available to support it.

\subsection{Mitochondrial membrane lipids and apoptosis}

\subsubsection{Mitochondrial pathway for apoptosis}

As discussed briefly above, mitochondria have an important role in the modulation of cell death. The "intrinsic" or mitochondrial pathway to cell death becomes activated in response to a variety of apoptogenic stimuli, such as growth factor deprivation, hypoxia, cell detachment, oxidative stress and DNA damage [42,43]. This process results in increased mitochondrial membrane permeability and ultimately in the release of pro-apoptotic factors such as cytochrome $c$ (cyt c), Smac/DIABLO, Omi/Htr2A, and AIF (apoptosisinducing factor) from mitochondria, leading to the activation of a highly complex and regulated cell death program. Several mechanisms have been proposed to occur during the permeabilization of $\mathrm{OMM}$, as will be described in the following section. Another pathway leading to apoptosis involves mitochondrial calcium overload, which triggers the opening of the mitochondrial permeability tran- sition pore (PTP) through a phenomenon termed mitochondrial permeability transition (MPT). In vitro, the MPT causes disruption of oxidative phosphorylation and mitochondrial swelling due to influx of water, leading to the rupture of the mitochondrial outer membrane (OMM) and subsequent release of pro-apoptotic factors [44]. Indeed, more than an in vitro-only effect, the MPT is a common phenomenon in tissue injury [45].

When cellular ATP levels become abnormally low, which may result from mitochondrial dysfunction, classical apoptotic triggers typically cause necrotic demise, showing that sustained ATP production is required for the cells to engage the apoptotic program [46]. Necrosis results in the swelling of the cell and the disruption of the plasma membrane, with consequent release of cellular content to the extracellular space. As opposed to apoptosis, uncontrolled necrosis triggers an inflammatory response that can cause further damage to surrounding cells [47].

\subsubsection{Mitochondrial membrane remodeling and signaling during apoptosis}

Several alterations in mitochondrial lipid content and distribution during apoptosis have been reported (Fig. 1B). An increase in diacylglycerol (DAG), monolysocardiolipin (MLCL) and phosphorylated phosphatidylinositol (PI) was described in mouse liver mitochondria. On the other hand, $\mathrm{CL}$ and linoleic acid-containing phosphatidylcholine (PC) contents were reported to be decreased, with the same trend observed in mitochondria from other origins [48]. These lipid changes appear to reflect a deficiency in the biosynthesis of PC, impacting downstream the remodeling of $\mathrm{CL}$, 
since this process requires PC species as acyl donors. Thus, an increase in MLCL is often concomitantly found with the initial loss of CL [49]. The content in other lysolipids (C16:0 and C18:1 lysoPC) also increases during the early stages of the apoptotic process [50] and may play a crucial, although not fully clarified, role in assisting the pro-apoptotic proteins Bax and Bak in the process of OMM permeabilization [48].

During apoptosis, OMM CL content has been reported to increase from very low to up to $40 \mathrm{~mol} \%$ of its total content [51]. On the other hand, CL distribution between the two leaflets of the IMM [52] was shown to change from 60:40 mol\% between the inner leaflet (matrix side) and the outer leaflet (intermembrane space side) to about 30:70 mol\%, during the early phase of apoptosis, with CL translocation to the outer leaflet of the IMM resulting in increased association with cyt $c$. Moreover, CL peroxidation was suggested to have a key role in mitochondrial apoptotic signaling. Thus, upon an apoptotic stimulus, a tight complex between cyt $c$ and $\mathrm{CL}$ is formed and cyt $c$ is converted from a loosely attached electron carrier protein to a peroxidizing molecule $[53,54]$. Then, a catalytic peroxidase activity selectively targeted towards CL is initiated. This oxidation process leads to a decrease of cyt $c$ affinity for $\mathrm{CL}$ and apparently mediates the release of pro-apoptotic factors from mitochondria into the cytosol, including cyt $c$ itself, by mechanisms not yet fully understood. [51]. Interestingly, CL as well as phosphatidylethanolamine (PE), predominates in IMM-OMM contact sites. These phospholipids are both non-bilayer lipids, adopting an inverted hexagonal phase $\left(\mathrm{H}_{\text {II }}\right)$ in the absence of membrane constraints. Although somehow speculative, it has been proposed that non-bilayer lipids could be involved in membrane fusion at the contact sites, fostering CL access to the cytosolic face of OMM [55], where it would directly interact with tBid, offering a docking site for this active form of the pro-apoptotic protein Bid. This would be the first step for triggering the action of Bax and Bak (other pro-apoptotic Bcl-2 proteins), thus leading to OMM permeabilization. A more recent view of the involvement of CL-enriched contact sites in apoptosis-associated events was presented by Sorice et al. [56]. In this work, a hypothetic model was presented proposing that contact sites act as activating platforms (raftlike microdomains) at which caspase- 8 is anchored, cleaving its substrate (Bid). The resulting product, $t B i d$, is then recruited to promote Bak/Bax oligomerization. The segregation of these domains from the rest of the OMM would create membrane defects, fostering apoptogenic factor leakage.

Sphingolipids also play a crucial role in the early stages of apoptosis. Mitochondria are provided with enzymes that catalyze the synthesis and the hydrolysis of ceramide, a lipid that occupies a central position in sphingolipid metabolism [57]. Thus, ceramide can be generated in the endoplasmic reticulum as well as in mitochondria [58] by de novo synthesis, which can involve the acylation of sphinganine to form dihydroceramide in a reaction catalyzed by ceramide synthase, or the reverse reaction of ceramide hydrolysis catalyzed by ceramidase, using as substrates sphingosine and fatty acids.

It is well known that ceramide levels in mitochondria undergo a significant increase prior to the onset of apoptosis. On the other hand, ceramide-induced adverse effects on mitochondria have been extensively reported, namely increased generation of ROS, alteration of calcium homeostasis, collapse of the inner mitochondrial $\Delta \Psi$ and release of proteins from the intermembrane space [59]. However, the mechanisms underlying ceramide-induced apoptosis at the mitochondrial level are not yet fully clarified. According to some authors [59-61], this event involves a direct action of ceramide on mitochondria, although the immediate consequences of this interaction and the role on apoptotic alterations are still under debate. Siskind et al. demonstrated that ceramide forms protein-permeable channels in isolated mitochondria, thus raising the permeability of the OMM not only to cyt $c$, but also to all small proteins (up to $60 \mathrm{kDa}$ in size) at physiologically relevant ceramide concentrations [60]. Interestingly, these channels, formed by transmembrane columns of ceramide molecules held together by intermolecular hydrogen bonds [59], were not formed within the plasma membrane of erythrocytes [60], revealing a certain specificity for the lipid environment of the OMM. Other authors alternatively proposed that the direct interaction of ceramide with the OMM results in its permeabilization due to the formation of ceramide-rich macrodomains which recruit Bax molecules, regulating their insertion and subsequent oligomerization to form pores [61]. Therefore, ceramide was proposed as a membrane-based stress calibrator, acting through a reorganization of the OMM structure. This effect is compatible with ceramide propensity to promote lateral phase separation in a fluid phospholipid membrane inducing the formation of extremely ordered and rigid ceramide-enriched platforms [62]. This has been proposed to serve clustering of receptor molecules, reorganization of signaling molecules and to constitute, at the plasma membrane level, sites to promote and amplify signaling processes [63]. As an alternative to a direct interaction of ceramide with mitochondria, the activation of the pro-apoptotic proteins BAX/BAK mediated by the sphingolipid metabolites sphingosine-1phosphate (Sph1P) and hexadecenal was proposed as the mechanism underlying OMM permeabilization [64]. According to this proposal, ceramide, constitutively generated from sphingomyelin by a neutral sphingomyelinase in a mitochondrial-associated compartment, is transferred to mitochondria and produces Sph1P and hexadecenal, which directly regulate BAK and BAX, respectively, by stabilizing the active conformation of these effector proteins. Hexadecenal, a product of Sph1P degradation, would promote BAX monomer conformational alterations that favored oligomerization, leading hence to permeabilization of OMM and apoptosis.

GD3, a ceramide-based glycolipid, has been reported to accumulate during apoptosis in mitochondria, where it is supposed to trigger specific events involved in the apoptogenic program by interacting with mitochondrial raft-like microdomains [65]. In fact, GD3-enriched raft-like domains are formed during Fas/CD95-mediated apoptotic signals, consisting of well-ordered structures connected to the internal mitochondrial cristae in mitochondria [66]. After a pro-apoptotic stimulus, a number of mitochondrial proteins, such as ATP synthase, VDAC-1, VDAC-2 [67] and hFis [68], converge to those raft-like mitochondrial microdomains, which contribute to apoptosis-associated modifications and late apoptogenic events, as previously mentioned [69]. GD3 was considered as an actual structural component involved in the formation of the PTP, and contributing to the formation of a multimolecular complex that includes VDAC-1, Bcl-2 family and fission proteins, such as hFis [68]. Following CD95/Fas crosslinking, Bax, Bak, caspase- 8 and tBid are also recruited to these CL- and GD3-enriched mitochondrial raft-like microdomains, as mentioned above $[66,56]$. Therefore, GD3 has been proposed as playing a crucial role in the context of MPT induction and cyt $c$ release and subsequent cell death promotion [66].

\subsection{Remodeling mitochondrial membrane lipids to survive: the case of cancer cells}

The classical metabolic phenotype of cancer cells consists of an increase in glycolytic fluxes under aerobic conditions, which was first described by Otto Warburg almost a century ago [70]. The Warburg effect involves a much more complex metabolic picture, involving the orchestration of multiple factors [71], and is reflected in pronounced alterations in bioenergetic and apoptotic-related cellular signaling. These can account for oncosuppression, oncogenesis, tumor progression and chemotherapy resistance shown by cancer cells, which are remarkably more resistant to death induction than their normal analogs [72]. Several specific 


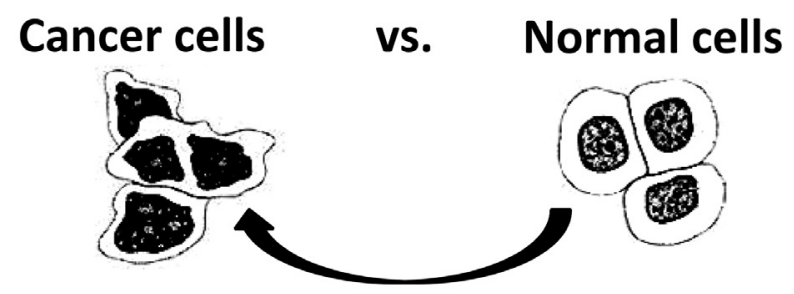

Mitochondrial alterations
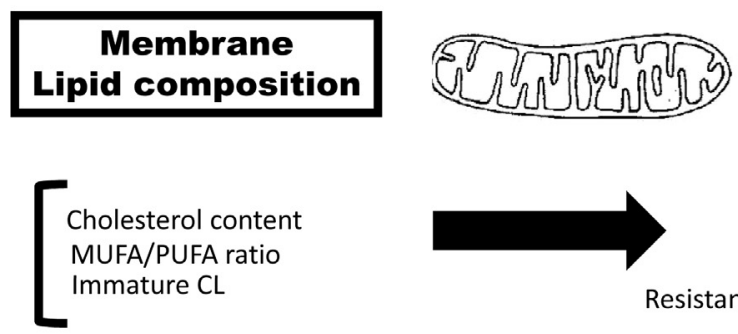

Mitochondrial
Physiology

MUFA/PUFA ratio

(1)
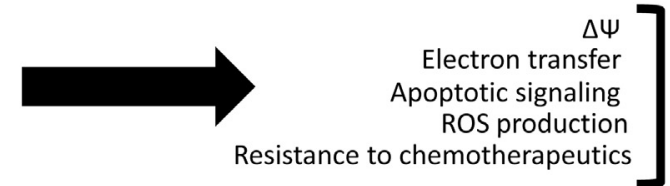

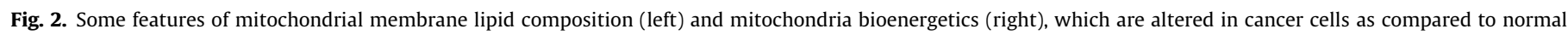

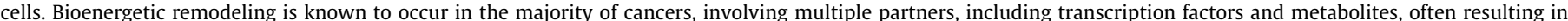

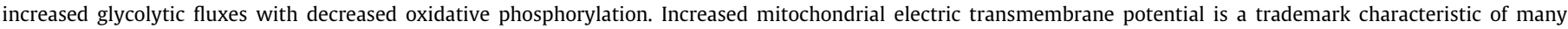

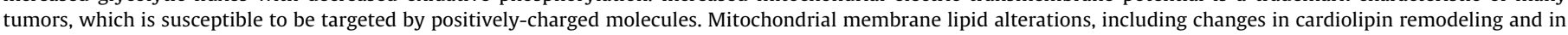

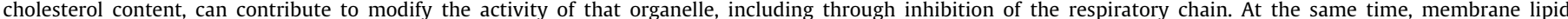

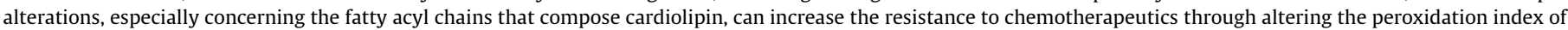
that phospholipid (MUFA/PUFA ratio).

alterations associated with mitochondrial function have been observed in cancer cells, with the activities of certain enzymes involved in oxidative phosphorylation being decreased in mitochondria from these cells. Increased gluconeogenesis and glutaminolysis, a decrease in pyruvate oxidation, increased lactate production accompanied by decreased fatty acid beta-oxidation have been reported in mitochondria from different types of tumors [73].

In the whole metabolic remodeling framework in cancer, the mitochondrial membrane composition was described to undergo alterations (Fig. 2). Analysis of the inner membrane lipid composition of various tumor mitochondria indicated an higher cholesterol content [74-76], along with changes in the relative amount of individual phospholipids [77]. Alterations in lipid acyl components have also been observed, the phospholipids of mitochondria from tumour cells showing generally shorter and less unsaturated acyl chains than those from normal cells $[78,79]$.

Lipid composition alterations in mitochondrial membranes are expected to impact the mitochondrial phenotype, which may contribute to the Warburg effect and to the decreased susceptibility to apoptotic stimuli. Altered mitochondrial membrane composition and dynamics in cancer cells may decrease the activity of the respiratory chain, a relationship that has already been described for CL [77]. On the other hand, a remodeling in mitochondrial membrane lipid composition may also contribute to the increased mitochondrial $\Delta \Psi$ observed in many tumors $[80,81]$. Increased mitochondrial $\Delta \Psi$ may have as a consequence an increased generation of ROS by the respiratory chain, which may be important in the context of cancer development, including by regulating Kras-mediated tumorigenicity [82], and stabilizing the hypoxia-inducible factor$1 \alpha$ [83]. The mechanisms underlying these phenomena appear to involve both protein and membrane lipid alterations. One possibility is that altered ATP synthase protein content/activity can decrease proton conductance through the $F_{o}$ subunit, increase mitochondrial $\Delta \Psi$ and decrease ATP generation thus contributing to the Warburg effect [84]. Uncoupling proteins (UCP) would also be an attractive candidate to explain those alterations, since a decreased expression of this class of proteins in tumors would in theory contribute to increase mitochondrial $\Delta \Psi$. Nevertheless, the still incomplete knowledge of the functional meaning of the different UCP isoforms justifies that the results obtained so far regarding the function of this class of proteins in different tumors is still under discussion [85,86]. In fact, an increase in UCP2 was identified in breast and in many other tumors, including leukemia, ovarian, bladder, esophagus and lung [87]. Ectopic expression of UCP2, surprisingly, was able to increase the tumorigenic properties of a breast cancer cell line. The authors proposed that increased expression of UCP2 results from an adaptive response to the hyperpolarization of mitochondrial membranes [87], showing that modulation of UCP2 content is a consequence and not a cause of hyperpolarized $\Delta \Psi$. In terms of membrane lipids, the cholesterol content has been shown to increase in the inner mitochondrial membrane of Ehrlich tumor mitochondria, an effect that was suggested to increase membrane order and decrease proton passive permeability through that membrane, thus increasing $\Delta \Psi[74]$. Other outcomes of mitochondrial membrane cholesterol enrichment include reduced activity of the respiratory chain [88], promoting a phenotype characteristic of the Warburg effect, and increased resistance to chemotherapy [75]. The role of cholesterol in chemotherapy resistance has been related to its capacity to increase membrane lipid packing, thus decreasing mitochondrial membrane permeabilization and impairing Bax-driven release of cytochrome $\mathrm{c}$ to the cytosol [75]. Some studies have suggested that the increase in cholesterol in mitochondrial membranes may be directly related with caveolin-1 deficiency [89], which has been described to underlie carcinogenesis in different models including colorectal and breast cancer [90,91]. Interestingly, loss of tumor stromal caveolin-1 leads to increased oxidative stress and induced the so-called "reverse Warburg effect", in which tumor-associated fibroblasts with deficient mitochondrial function and increased oxidative stress and autophagic fluxes feed tumor cells with substrates for the respiratory chain $[91,92]$. Other studies have suggested that the outer membrane protein voltage-dependent anion channel (VDAC) is involved in cholesterol distribution in mitochondrial membranes in tumors [88].

CL has also attracted a lot of interest in a cancer context. A shotgun lipidomics study aiming at determining CL content and composition in mitochondria from subcutaneously grown brain 
tumors including astrocytoma and ependymoblastoma, a stem cell tumor, and two microgliomas, showed evident alterations in CL content and composition in all tumors [77]. These abnormalities included an abundance of immature molecular species along with alteration of mature molecular species, probably related to defects in CL synthesis and remodeling. Data regarding this mitochondrial phospholipid in terms of cancer are very diverse, ranging from the appearance of immature molecular species and decreased CL content in brain tumors [77], decreased CL content in rhabdomyosarcome cells [93], increased CL content and fatty acid remodeling in a rat model of peritoneal carcinosis [94] to unaltered total CL amount in a mouse strain with high propensity to form spontaneous gliomas [95]. This last study involved two strains of mice, one of which $(\mathrm{VM} / \mathrm{Dk})$ with a much higher propensity to develop gliomas than the other, taken as the control strain (C57BL/6J). The VM/ Dk strain not only contained higher amounts of ethanolamine glycerophospholipids, phosphatidylserine (PS) and ceramide, but also displayed a lower number of $\mathrm{CL}$ species than the control strain [95]. Interestingly, although the activity of complexes I-III was decreased in the VM/Dk strain, complex IV activity was higher [95]. This disparity of impact on respiratory chain activity may have resulted from the differences in CL species, which should have influenced the rate of ROS production and ATP generation, although sadly these parameters of mitochondrial function have not been measured in this work.

Regarding the drug resistance phenotype, studies on MCF-7 human breast cancer cells showed an increase of CL content (expressed in percentage of cell total phospholipids) in doxorubicinresistant and cisplatin-resistant cancer cells, as compared to drug-sensitive parental cells [96]. However, other lipid alterations were observed in those drug resistant cells, namely an increase in cholesterol and sphingomielyn content, which the authors suggest to be involved in lipid raft dynamics, thus affecting protein-protein and protein-lipid interactions. The characterization of CL species in drug-sensitive vs. drug-resistant cells was not performed in this study. Evidence has been obtained that CL remodeling is important in determining CL peroxidation catalyzed by cyt $c$ and consequent cyt $c$ dissociation from the inner mitochondrial membrane [53,54]. Therefore, the decreased resistance to apoptosis in tumor cells may be predictably related with less oxidizable CL species. In terms of $\mathrm{CL}$ content and its relationship with cell resistance to apoptosis, a very comprehensive study has been carried out by Huang et al. [37] showing that CL deficiency counteracts rather than promotes, as stated by other authors [97], cytochrome $c$ release and apoptosis induced by several stimuli. Huang and collaborators remarked that discrepant results obtained by Choi et al. might be due to the methodology used for $\mathrm{CL}$ quantification: a radioactive method based on the integration of $\left[{ }^{3} \mathrm{H}\right]$ palmitic acid into phospholipids instead of evaluating the content of $\mathrm{CL}$ with respect to the total phospholipid phosphorus, as performed by Huang et al. These authors argued that, since palmitate has shown to be a poor substrate for CL synthase [98], a predictable low incorporation of the radiolabel in CL should have occurred, thus disabling an accurate determination of $\mathrm{CL}$ content changes relative to other lipids.

Facing these different results, it is not easy to establish a model for the effects of CL on cancer etiology. As a general consequence, we may anticipate that alterations in CL:protein ratio or in CL species may alter the activity of different respiratory chain proteins, thus inhibiting electron flux and the efficiency of oxidative phosphorylation [94], contributing to the Warburg phenotype. But the story is certainly far more complex. The balance between proapoptotic and anti-apoptotic proteins present in the OMM, critical in the context of apoptosis, is altered in a variety of tumors. In fact, the mitochondrial apoptotic pathway is compromised by a readjustment between anti-apoptotic and proapoptotic promoters, in favor of the former [99].
Targeting mitochondrial alterations has become a promising strategy for the induction of apoptosis in tumor cells. The aforementioned proliferative and bioenergetic differences between normal and tumor cells provide an opportunity to selectively target cancer cell mitochondria or even use them as biomarkers for early detection of cancer $[71,73]$. As an example, the above mentioned differences in $\Delta \Psi$ have been used as part of a therapeutic strategy, in which delocalized lipophilic cations are selectively accumulated in tumor cells. Some of these compounds have in fact exhibited efficiency in the demise of cancer cells either in vitro or in vivo [100-108]. However, efficient mitochondrially-targeted therapies must be based on the coordinated targeting of as much cancer features as possible, namely cellular energy metabolism, mitochondrial stability and mechanisms responsible for apoptosis resistance [109].

In summary, this section highlighted a particular case of mitochondrial membrane remodeling towards cell survival and fast proliferation, with different examples pointing to lipid membrane and protein alterations in tumors, which can contribute to the Warburg phenotype and to escape from basal or chemotherapy-induced cell death. Cardiolipin appears to be particularly involved in this process, a phenomenon that is observed in the context of other human pathologies (see the following section).

\subsection{Cholesterol and cardiolipin alterations in human disease: beyond cancer}

Several pathologic conditions have been proposed to promote changes in mitochondrial lipid composition, which may be implicated in alterations of mitochondrial function and in disease progression. Two lipids will be specially focused in this section: CL and cholesterol. Alterations associated with CL content and fatty acid composition have shown to play an important role in a disease context. Reduced CL levels (the most frequently reported pathological alteration regarding this lipid) [110], CL oxidation and/or alteration of its molecular composition have been associated with mitochondrial dysfunction in multiple tissues and in several physiopathological conditions, including ischemia/reperfusion, different thyroid states, diabetes, heart failure and Barth syndrome [111-115]. An important note of caution is that in most cases there is no definitive evidence whether the alteration in CL amount/species is located upstream or downstream of the disease process and the impact of that specific defect on the overall mitochondrial phenotype.

\subsubsection{The Barth Syndrome}

Barth Syndrome (BTHS) is a paradigmatic example of a disease in which a clear association between the pathological phenotype and a defect on a mitochondrial lipid has been established. BTHS is an X-linked disease [116], often fatal in childhood and resulting in congestive heart failure in infants [117]. This multisystem inherited disorder is characterized by cardiomyopathy, skeletal myopathy, growth retardation, neutropenia and organic aciduria [118120]. A broad spectrum of clinical manifestations, with different levels of severity, has been observed in BTHS patients, which complicates the diagnosis of the disorder, due to the difficulty in differentiating it from other cardiomyopathy syndromes in infants, based solely on clinical findings.

Studies of familial cardiomyopathies have shown that this disease is linked to the TAZ or G4.5 gene (previously termed tafazzin), located at Xq28 [116], which is highly expressed in the cardiac and skeletal muscle. The primary transcript of this gene can produce different mRNAs by alternative splicing, producing proteins that differ at the N-terminus and at the central region [116]. The detection of a significant sequence homology between the TAZ gene and genes coding for phospholipid acyltransferases led to the hypothesis that impairment of lipid metabolism should be involved in 
BTHS [121]. Abnormalities of the respiratory chain, not confined to a specific respiratory complex, were detected in mitochondria from different cells of BTHS patients [122,123], strengthening the hypothesis that the cause of this disease resided on membrane lipid composition alterations with consequent perturbation of lipidprotein interactions. The impairment of mitochondria function, in turn, could explain the occurrence of characteristic clinical manifestations of BTHS, such as cardiomyopathy and muscle weakness. Since CL plays a crucial role in mitochondria complex assembling, stability and function [124,32], it would not be surprising that TAZ mutations impacted on CL homeostasis. In fact, a decrease of $\mathrm{CL}$ content [117] and alterations in CL remodeling/maturation, reflected in impaired incorporation of linoleic acid into CL [125] and a specific decrease of tetralinoleoyl-CL $[117,126]$, were reported in a variety of tissues from BHTS patients. An extensive study involving children with genetically proven BHTS and children exhibiting BTHS-like disorders (lacking TAZ mutations) showed that $\mathrm{CL}$ analysis in platelets can provide a valuable diagnostic tool to identify cardiomyopathies caused by TAZ mutations, since only in this case CL abnormalities were detected [117]. However, besides $\mathrm{CL}$, other phospholipids, namely phospatidylcholine and phosphatidylethanolamine (PE), exhibited a non-characteristic fatty acid composition, resulting in a deficiency of palmitoyl-arachidonoyl-glycerol species in several tissues, with potential impact on eicosanoid-dependent signal pathways [117].

The synthesis of characteristic CL species in mitochondria involves two steps: (a) transfer of an activated phosphatidyl group from phosphatidyl-cytidine monophosphate to phosphatidylglycerol (PG), catalyzed by cardiolin synthase and (b) CL molecule remodeling by tafazzin-catalyzed transacylation, in order to produce cell and tissue-specific CL species, namely tetralinoleoyl-CL, a dominant molecular species in animal and plant tissues [127]. Therefore, it is conceivable that alterations of the characteristic $\mathrm{CL}$ acyl-composition detected in BTHS result from impaired tafazzin activity. On the other hand, accumulation of MLCL molecules has been associated with BTHS [128]. Malhotra et al. [129] stated that this effect was due to the action of a mitochondrial calciumindependent phospholipase $\mathrm{A}_{2}$ (iPLA $\mathrm{iPIA}_{2}$ ), which promoted $\mathrm{CL}$ deacylation. Using a tafazzin-deficient Drosophila model of BTHS, which exhibited poor motor function in parallel with abnormal mitochondria, low CL content and CL species with abnormal fatty acid composition, the authors demonstrated that the inactivation of mitochondrial calcium-independent iPLA $\mathrm{A}_{2}$-VIA could be a strategy to revert manifestations associated with tafazzin deficiency [129]. Also, the chemical inhibition of calcium-independent phospholipase $\mathrm{A}_{2}$ from Barth patient lymphoblasts restored the MLCL/ $\mathrm{CL}$ ratios to the values detected in normal cells. Since an important consequence of TAZ mutations that contribute to BTHS is related to MLCL accumulation, the inhibition of the deacylation step should be envisaged as a partial solution of the problem. On the other hand, this therapeutic intervention should spare healthy cells and target specifically the tissues affected by the disorder.

Another interesting issue concerns the specificity of CL acyl patterns, resulting a priori from fostering specific transacylations in normal mitochondria. Recent studies showed that tafazzin itself does not display a high specificity for their lipid substrates, reacting with a great variety of phospholipids and lysophospholipid species [130-132], although its activity is greatly influenced by the physical properties of the matrix in which lipid substrates reside [130], being lower for lipids highly packed in bilayer phases. Moreover, Schlame et al. [130] showed that the characteristic CL species of normal mitochondria (tetralinoleoyl-CL) could be formed in vitro in the presence of purified tafazzin, under conditions that favor inverted hexagonal lipid arrangements. It was thus proposed that tafazzin acts in specific membrane lipid domains, explaining why its activity does not equilibrate the fatty acid composition of all mitochondrial phospholipids [130,133]. On the other hand, tafazzin-induced formation of tetralinoleoyl-CL (a non-bilayer lipid) in highly curved lipid domains is expected to have a great impact on fostering mitochondria fission and fusion phenomena, which require transient destabilization of lipid bilayer, or on favoring lipid arrangements in membrane regions with very high curvature, such as those in contact sites between the inner and outer mitochondrial membranes. Notably, these regions are enriched in $\mathrm{CL}$ and seem to play a crucial role in clustering and organization of apoptotic signals on mitochondria [56], as previously reported in this work.

\subsubsection{Cardiac pathology}

A loss of heart mitochondria CL following ischemia has been described in the early 1980s [134,135], and has since been well documented in a variety of tissues. CL depletion accompanied by loss of cytochrome $c$ during the ischemia phase was shown to lead to increased generation of hydrogen peroxide by the respiratory chain [136]. On the other hand, chronic cardiac overload leading to experimental heart failure, results in loss of tetralinoleoyl-CL with consequent decrease in the activity of cytochrome $c$ oxidase [115]. A similar effect was observed in rats suffering from rapid pressure-overload hypertrophy and failure by chronic aortic banding. In this case, a reduction in the linoleoyl content in cardiac mitochondria CL was reported $[137,138]$. A reduction of heart CL content was also reported during the progression of heart failure in cardiomyopathic hamsters. The authors of this report ascribed this event to a reduction of the diacylglycerol content in heart and impaired phospholipid biosynthesis [139]. CL loss during cardiac pathologies may result from deficient biosynthesis/remodeling or increased degradation (including oxidation) and certainly affect mitochondrial energy generation [140].

\subsubsection{Diabetes and other metabolic diseases}

Recent reports indicate a reduction of mitochondrial CL levels and alterations of $\mathrm{CL}$ acyl chain remodeling, resulting in increased incorporation of the highly unsaturated docosahexaenoic acid, in the hearts of streptozotocin (STZ)-treated diabetic mice [141]. Whether these specific CL alterations, occurring in an early stage of diabetes, influence the development or progression of diabetic cardiomyopathy remains unknown. A recent study demonstrated that transgenic expression of $C L$ synthase decreases the incidence of $C L$ remodeling processes that ultimately cause degeneration of mitochondrial function during STZ-induced diabetes [142]. Not only mitochondrial dysfunction was mitigated by cardiolipin synthase expression in the diabetic myocardium, but also a marked increase in protective eicosanoids was observed [142]. Although this interesting study allows foreseeing a therapeutic role for this enzyme within the scope of diabetes-induced alterations of mitochondria bioenergetics and signaling, the truth is that we are far from understanding the mechanisms underlying the benefic effects resulting from the manipulation of cardiolipin synthase.

In another context, an increase in CL synthase activity and CL content in rat heart [143-145] and liver mitochondria [146] was found in hyperthyroidic rats, which resulted in an increase in the activity of multiple CL-dependent mitochondrial proteins and processes. Conversely, drug-induced hypothyroidism resulted in a marked loss of CL content and CL synthase activity in heart mitochondria [147]. This study also showed that rat heart monolysocardiolipin acyltransferase activity is regulated in parallel and in a concerted manner with the biosynthesis and content of cardiac CL.

A significant decrease in CL mitochondrial content and a relevant increase in the level of peroxidized $\mathrm{CL}$ were reported in non-alcoholic fatty liver disease. These changes in CL content were related to the decrease in complex I activity found in liver mitochondria from rats to which this disease was diet-induced, since 
the activity of complex I was completely restored to the level of control livers by exogenously added CL. Moreover, the effect of exogenous CL was not reproduced by other phospholipids nor by peroxidized CL [148].

\subsubsection{Parkinson's disease and oncogenic-associated cachexia}

Intriguing evidence for a potential role of CL alterations in Parkinson's disease has been provided [149]. Mice lacking $\alpha$-synuclein exhibited a $22 \%$ reduction in CL mass in the brain, a $25 \%$ reduction in the $\mathrm{CL}$ content in $\mathrm{n}-6$ polyunsaturated fatty acids (including C18:2), and a $51 \%$ increase in the CL content in saturated fatty acids. A 23\% reduction in PG (a CL precursor) was also detected, without any changes in the content of other brain phospholipids or mitochondrial density, suggesting that the CL biosynthesis pathway should have been selectively impaired.

Cachexia is a serious consequence of a carcinogenic process. Inflammation and disruption of metabolic and energy balance result in a decrease of body mass, mostly originating from a depletion of muscle tissue [150]. Using animal models of peritoneal carcinosis, a decreased efficiency of liver mitochondrial function was observed, concomitantly with an increase in energy wasting and with a lower $n-6 / n-3$ PUFA ratio in the carcinosis group, as compared to the control group [94]. Interestingly, very large (12-fold) increase in ROS generation by hepatic mitochondria was observed in the same group [94]. Although this alteration was not investigated in other tissues (namely skeletal muscle), this investigation makes way for therapies aimed at improving mitochondrial efficiency to prevent cachexia derived from different pathologies, including cancer. Moreover, a recent review [151] provided clues suggesting that alterations in CL composition may be behind a decrease in mitochondrial efficiency in cancer cachexia.

\subsubsection{Drug-induced mitochondrial toxicity}

Cardiolipin has also been involved in the mechanisms of toxicity of several drugs. One particular example is Doxorubicin (DOX), an anti-cancer agent whose clinical usage is associated with a cumulative and dose-dependent cardiotoxicity, in which mitochondria appear to play an important role [152-154]. DOX inhibits the activity of several mitochondrial proteins in the heart [155157], which result from a specific drug interaction with CL, excluding this phospholipid from the lipid matrix surrounding the protein complexes indirectly affected by DOX [158-160]. Recent data demonstrated that tacrine, an acetylcholinesterase inhibitor used in the treatment of Alzheimer's disease, promotes a significant disturbance in the mitochondrial phospholipid content in the brain of treated rats, including a decrease in CL and an increase in oxidized aminophospholipids [161].

On the other hand, a great diversity of mitochondrial-active molecules, such as the anti-inflammatory nimesulide [162], the protonophore carbonylcyanide p-trifluoromethoxyphenylhydrazone (FCCP) [163] and the precursor of vitamin $\mathrm{K}$ menadione (2methyl-1,4-naphthoquinone or vitamin K3) [164] disturb lipid order and organization in mitochondrial membrane-mimicking models, which may contribute to the adverse mitochondrial effects exerted by those compounds. Non-lamellar CL-containing structures induced by FCCP and menadione were suggested to have a key role in the insertion of those molecules in IMM lipid milieu and influence lipid and protein topology, namely in CL-enriched regions such as the contact-sites, with predictable impact on mitochondrial functioning.

\subsubsection{Mitochondrial cholesterol alterations and disease}

Accumulation of cholesterol in mitochondria seems to be a key step in the progression of some pathologic conditions, including steatohepatitis, carcinogenesis and Alzheimer disease [165].
Interestingly, Alzheimer disease has been considered as a disorder of mitochondria-endoplasmic reticulum (ER) crosstalk, which occurs through mitochondria-associated ER membrane (MAM) [166]. This ER sub-domain, which is physically connected to the OMM, constitutes a crossroad between signal transduction and metabolic pathways, with impact on mitochondria function and, hence, on cell fate [167]. In recent years, this membrane compartment has deserved special attention in a lipidomic perspective, since it has been recognized as an intracellular lipid raft-like structure, enriched in cholesterol and sphingolipids organized in a liquid-ordered phase, thus promoting an increased thickness of the bilayer as compared to the surrounding ER membrane [166]. Such structural characteristics make MAM able to recruit certain proteins, excluding others. Among others, proteins whose transmembrane domains favor a "hydrophobic matching" with MAM bilayer will be preferentially selected to reside in that region. According to the "MAM hypothesis" for AD [166], the key catalytic component of the $\gamma$-secretase complex (presenilin), its substrate (APP, from amyloid- $\beta$ precursor protein) and $A \beta$ (the small peptide that results from the processing of APP) are enriched in MAM. On the other hand, Winkler and collaborators [168], carrying out a systematic study on the activity of $\gamma$-secretase reconstituted in membrane model systems differing in the thickness of the lipid bilayer showed that the generation of the long toxic $A \beta$ with $42 / 43$ amino acids is significantly higher in thinner membranes, probably as a consequence of changes in presenilin I conformation or tilting. Therefore, the authors proposed the regulation of the thickness of $\gamma$-secretase host membrane as a new potential target for AD therapy.

Cholesterol also regulates the association between mitochondrial and endoplasmic reticulum (ER) membranes in MAM [169], which means that disturbances in cellular cholesterol content alters the association between the two organelles, predictably with important consequences for the cell. In fact, a tighter membrane association (apparently favored by cholesterol depletion [169]) has been found to promote apoptosis resulting from $\mathrm{Ca}^{2+}$ mitochondrial overloading.

Another important aspect related to cholesterol regards the role of caveolin-1, an important component of caveolae, which are invaginations of the plasma membrane, rich in cholesterol and with important roles in membrane trafficking and cell signaling [170]. Caveolin-1, however, is also hosted in MAM and induces cholesterol efflux from the ER to the plasma membrane, reducing MAM cholesterol content and its entry into mitochondria [89]. Thus, caveolin-1 deficiency causes free cholesterol accumulation in mitochondrial membranes, increasing membrane order, decreasing electron flux through the respiratory chain and increasing ROS generation and apoptotic signaling [89,171], which can be related to the progression of several diseases. The consequences of caveolin-1 depletion in cancer were previously described in Section 2.2.

\subsection{Mitochondrial membrane lipid composition changes in aging}

The free radical theory of aging [172] stated that normal aging is the result of the oxidative damage to tissues mediated by free radicals produced as a byproduct of oxidative metabolism. Subsequently, mitochondria have been seen as the main source and target of free radicals in the context of aging [173]. Progressive loss of mitochondrial function has been associated with aging and several experimental evidence have supported this interdependence [174], including: (i) the occurrence of mitochondrial DNA (mtDNA) deletions, punctual mutations or depletion; (ii) age-dependent decline in the activity of mitochondrial electron transport complexes; (iii) increase in the production of oxygen free radicals; (iv) changes in the morphology of mitochondria and (v) decrease or collapse of 


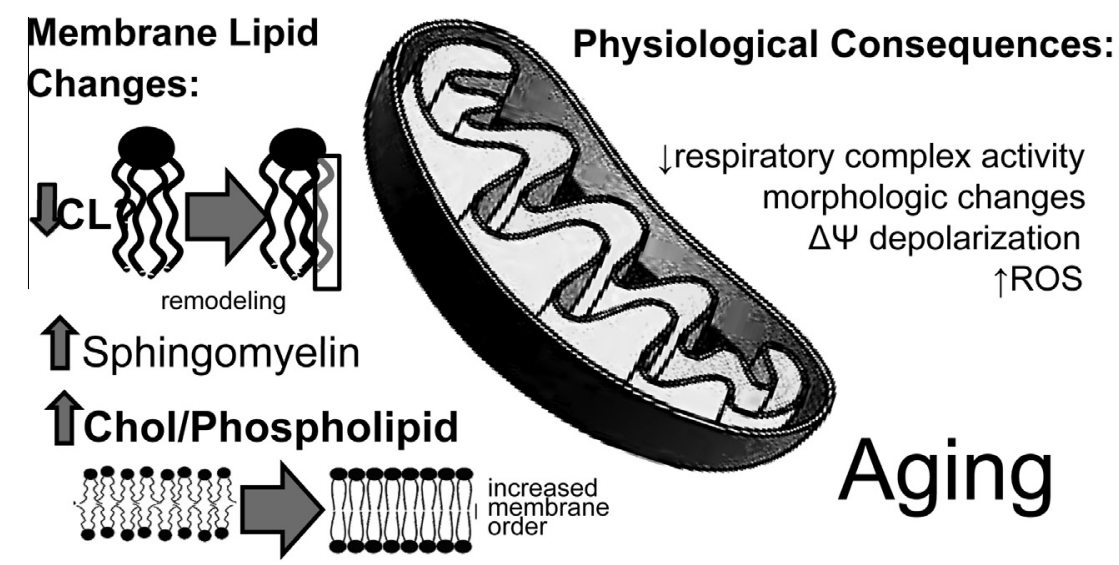

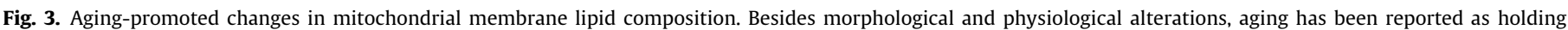

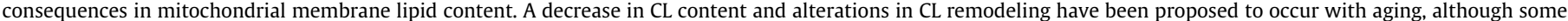

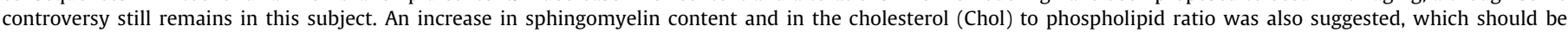

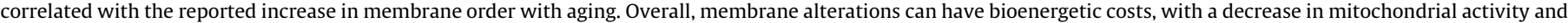
ATP production.

transmembrane $\Delta \Psi$. Loss of mitochondrial apoptosis regulation has also been reported in aged cells [175].

The membrane theory for aging conceives life span as being inversely related to the content in unsaturated membrane phospholipids [176]. A positive impact of calorie restriction has been suggested in this context, leading to a decrease in mitochondrial ROS production in multiple tissues [177] and extending mean and maximum lifespan in a variety of species [178]. Since lipid peroxidation is closely related to ROS-induced toxicity, the benefic effect of calorie restriction on the aging process is attributed to a decrease in membrane fatty acid unsaturation, thus diminishing lipid peroxidation [179]. Concordantly, calorie restriction has been reported to decrease the content in PUFAs in membranes from a number of tissues [180-182].

Changes in mitochondrial membrane fatty acid composition can also influence oxidative stress by promoting changes in membrane-mediated processes such as proton leakage across the IMM [183]. Other aging-induced alterations, such as decreased membrane fluidity resulting from lipid peroxidation, as well as decreased CL content and altered activity of the respiratory chain have been reported (Fig. 3). Due to the influence of CL in the activity of several anionic carrier systems [184-186] and some of the electron transport complexes [187-191], including their supramolecular arrangements [192,193], alterations in CL content may account for the reported age-dependent decline in mitochondrial performance [183]. In fact, this has been supported by data obtained in rat heart $[194,195]$, brain [196] and liver mitochondria [197], as well as in human epidermal cells [198]. Paradies and co-workers reported a consistent age-dependent loss of cardiac mitochondrial CL, correlated with a decreased activity of a number of proteins including the mitochondrial phosphate transporter [199], cyt $c$ oxidase [200], adenine nucleotide transporter [200], carnitine-acylcarnitine translocase [201] and the pyruvate carrier [202]. It was demonstrated that acetyl-L-carnitine restored the function of all those CL-dependent proteins by restoring the levels of $\mathrm{CL}$, although the molecular mechanism underlying this effect had not been clarified. The authors hypothesized an eventual influence of acetyl-L-carnitine in the activity of CL synthase [202]. However, a selective reduction of $\mathrm{CL}$ content with aging is still controversial, since other studies reported no alteration [203] or even an increase [204] in CL content in rat heart mitochondria, although in the former the alteration was detected only for interfibrillar mitochondria in Fischer 344 rats. CL remodeling is likely to be affected during the aging process. Several studies suggest that CL remodeling may be altered during aging, including an increase in the content of highly unsaturated fatty acids, namely arachidonic and docosahexaenoic acids, and a decrease in linoleic acid content in aged rat heart mitochondria [205], whereas another study showed an increase in CL long chain saturated fatty acids (arachidic and lignoceric acids) [204]. Similar changes were not observed in other phospholipid classes, namely in PE [204-206], or plasma unesterified fatty acids [205], suggesting the specificity of the alterations towards CL.

With regard to changes in the amount of other membrane lipids, a decrease in total phospholipid with a parallel increase in cholesterol, resulting in a progressive aging-dependent increase in the molar ratio of cholesterol/phospholipid, have been reported in hepatic mitochondria from aged animals [207]. Paradies et al. also reported an increase in cholesterol (43\%) and a decrease in the phospholipid content (15\%) in heart mitochondria, with CL being the principal responsible for phospholipid loss (28\% decrease in aged rats) [195]. Another study reported higher cholesterol content in heart mitochondria, along with an increased percentage of sphingomyelin [204]

Decreased mitochondrial membrane fluidity, as previously mentioned, also seems to be a characteristic of aging. Vorbeck and colleagues [207] reported a significant aging-dependent increase in the lipid structural order as measured by steady-state fluorescence polarization using the probe 1,6-diphenyl-1,3,5-hexatriene, which might be correlated with the increased cholesterol/ phospholipid molar ratio discussed before. A similar effect was reported for brain mitochondria [208].

Altogether, the abovementioned data suggest that the aging process is associated with a progressive remodeling of mitochondrial membranes, which impacts the capacity of mitochondria to generate ATP and to control apoptotic signaling (Fig. 3). One of the key players appears to be $\mathrm{CL}$, which has a relevant and critical role in both aspects. Therefore, it is expectable that strategies able to delay the loss of $\mathrm{CL}$ or avoid CL detrimental alterations should also delay the loss of mitochondrial capacity and ROS generation, possibly preventing in this manner some of the cellular phenotypes associated with aging. An interesting open question in this regard is whether the possible CL alterations occurring during aging, often resulting in mitochondrial dysfunction, can be reversed by diet or exercise. And, in this case, it would be challenging to identify the mechanisms involved, in order to improve potential strategies to counteract the aging process. 


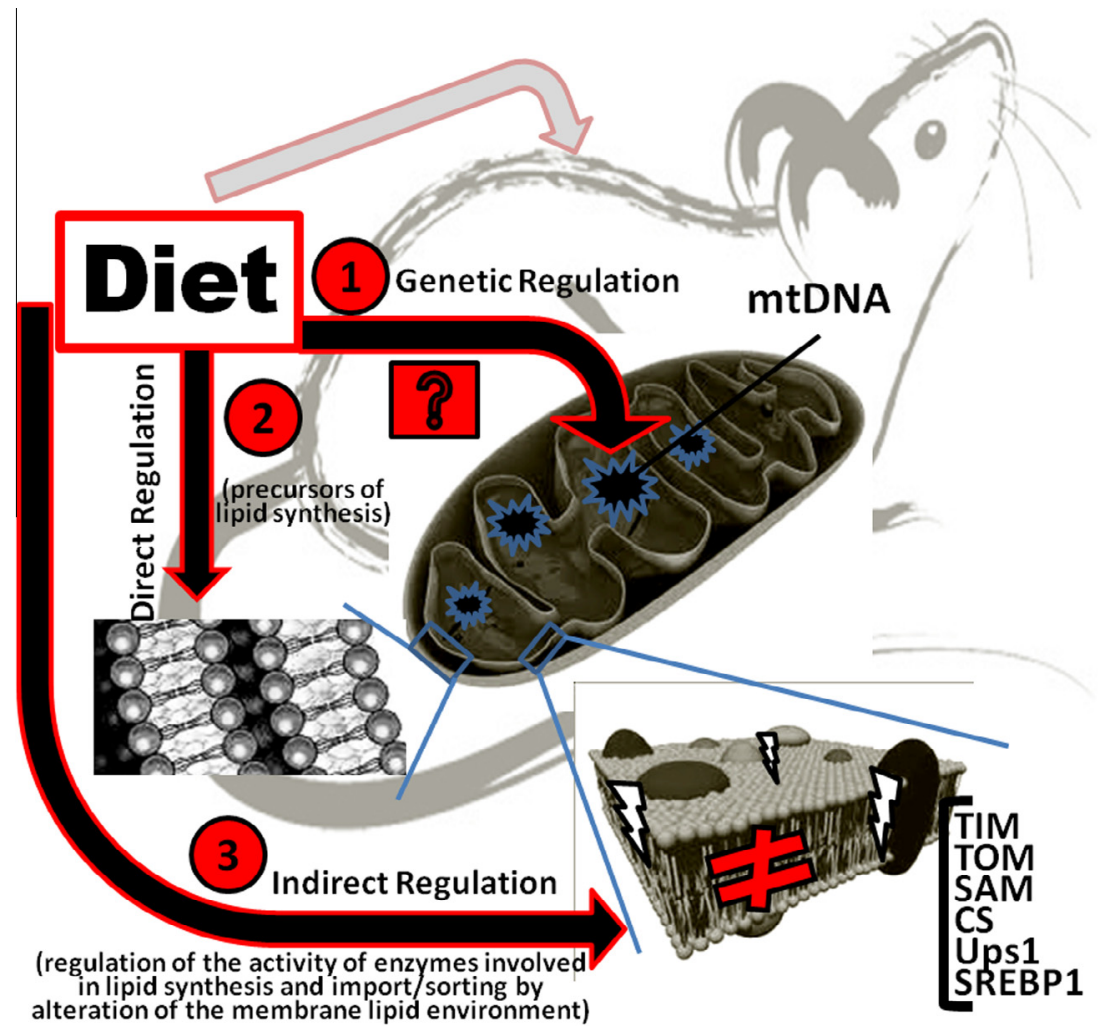

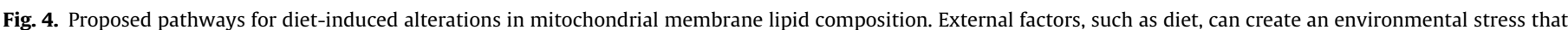

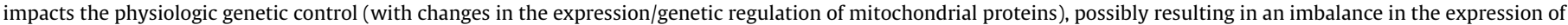

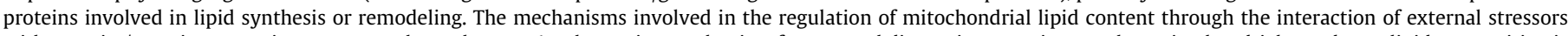

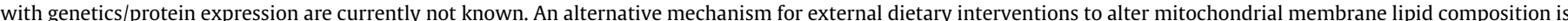

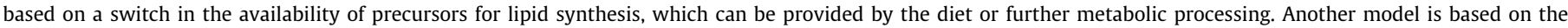

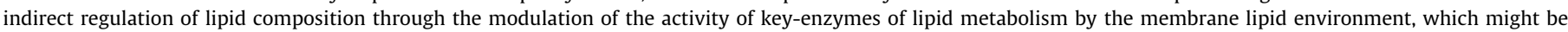

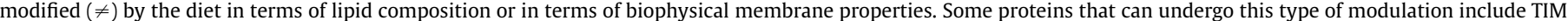

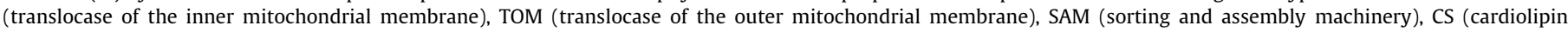
sinthase), Ups1 and SREBP1 (sterol regulatory element binding protein 1).

\section{Mitochondrial membrane lipids as a target for diet interventions}

As previously mentioned, mitochondrial lipid composition, although obeying a characteristic pattern, displays a highly dynamic behavior, depending on the physiological or pathological conditions. This plasticity in lipid composition, sensible to external modulation may substantiate the emergence of therapeutic applications. In fact, by modulating the lipid composition of mitochondrial membranes and, hence, interfering with mitochondrial function, it is predictably possible to regulate and improve mitochondrial function in the context of injury and disease (Fig. 4). In this context, the investigation of the mitochondrial alterations induced by diets with different fat composition can be instrumental to influence cell fate. Studies establishing a correlation between diet, mitochondria membrane lipid composition and mitochondria/cell physiology will open new trends to identify the etiology of diseases and to develop novel therapeutic strategies. One possibility is to establish dietary interventions that counteract or prevent alterations of membrane lipid properties associated to the occurrence of several diseases. In fact, dietary benefits have been revealed for some diseases, namely cardiovascular. Increasing evidence regarding a correlation between the prevalence of cardiovascular diseases in mammals and the type of lipids included in the diet has been found [209-211]. Benefits provided by tuna fish and sunflower seed oils were observed in cases of reduced ventricular fibrillation in occlusion, ventricular tachycardia and risk of sudden cardiac death [212]. Fish oil also proved to be advantageous against reduced atherogenesis, mortality from coronary heart disease, intimal hyperplasia and atherosclerosis [213-217]. Preventive effects and cardioprotective properties have also been reported for rapeseed oil (optimized oils) [218], including reduction of mortality rate and infarct size [219]. Thus, this oil has been suggested to be used as a functional supplement, aiding in stroke prevention and protection. Dietary benefits towards some kinds of cancer have also been reported, with an inverse correlation between fish oil consumption and the occurrence of male and female colorectal cancer [220] and breast carcinoma [220,221]. Advantages of a dietary control have also been proposed for type 2 diabetes [222]. Some mitochondrial fatty acid oxidation disorders may be targeted by dietary intervention, as well [223].

The importance of diet as a valid therapeutic approach is illustrated by the manageable modulation of the acyl chain unsaturation in CLs. In fact, CL was suggested to be more susceptible to undergo acyl chain changes upon dietary manipulation as compared to other phospholipid classes, such as PC and PE [224]. On the other hand, some studies revealed that tetraoleoyl-CL did not undergo oxidation when cyt $c /$ tetraoleoyl-CL complexes were incubated in the presence of $\mathrm{H}_{2} \mathrm{O}_{2}$ [51]. In this context, the enrichment of mitochondrial membranes with non-oxidizable molecular species of CL was proposed as a potential mechanism for protecting cells against apoptosis [51]. Conversely, an increase in PUFAs, resulting in increased generation of highly oxidizable CL species, would make the targeted cells more susceptible to oxidative modification and, ultimately, to 
apoptotic cell death. This approach may represent an interesting perspective when attempting to develop antitumor strategies to overcome the increased resistance of tumor cells to pro-apoptotic drugs [51].

We have also demonstrated recently that rats fed a rapeseed oil-rich diet for 11, 22 and 33 days undergo alterations of mitochondrial membrane lipid composition and properties, as well as a decrease in state 3 respiration [20]. This study demonstrated that the modified diet resulted in a higher incorporation of oleic acid in CL species [20], as well as in a decrease in hydroperoxide production by the respiratory chain [20]. One particular learning from these experiments was that lipid content of mitochondrial membranes was altered after only 11 days of modified, rapeseed oilbased diet, suggesting that diet can have an immediate effect on the composition (and properties) of mitochondrial membranes, modulating the bioenergetics of that organelle.

In another approach, recent data demonstrated that the dietary content in fatty acids modulated the type of CL species found in the liver of rats with non-alcoholic fatty liver disease [225]. Interestingly, different dietary fatty acid patterns (lard-rich vs. fish oil-rich diet) showed to modulate differently CL synthase gene expression and CL remodeling. Concomitantly, the activity of mitochondrial proteins was differently affected. While ATP synthase activity showed a positive correlation with increased CL content, the opposite was observed for complex II + III activity [225]. The differential effects of dietary fatty acid patterns on CL species impact mitochondrial capacity, which, in its turn, may interfere with beta-oxidation of fatty acids, thus resulting in progression of the disease.

Taking all previous data into account, it seems fair to emphasize the relevance that dietary approaches may hold in a therapeutic context. The synergistic effects of diet and pharmacological drugs, namely mitochondria-active compounds, could also represent a valid path to explore.

Some evidence have been accumulated underlining the influence of dietary lipids in the action of certain membrane-active drugs (e.g., anesthetics and alcohols) [226]. A correlation between diet-induced changes in membrane lipid composition and the pharmacological effects of volatile anesthetics, such as halothane, isoflurane, methoxyflurane and cyclopropane, has been established [227]. The authors demonstrated that the increased anesthetic action in rats fed a fat-free diet was specifically reversed by linoleic acid supplementation. The action of the local anesthetic tetracaine was also proposed to be dependent on lipid membrane composition [228]. Curcumin, a natural spice used for generations in traditional medicines, was proposed to indirectly regulate the action of membrane proteins by changing the physical properties of the membrane rather than acting by direct binding to proteins [229]. Similarly, many other molecules, including drugs and environmental contaminants, particularly those whose lipophilicity implies a strong incorporation into the lipid bilayer, have shown a biological activity mediated or highly influenced by direct interactions with membrane lipids [230-239]. Therefore, it is fair to assume that biological effects of such compounds should be modulated by an appropriate diet.

Focusing specifically on mitochondria, it was reported that the ATPase of heart mitochondria from animals fed diets with an high content in long chain-fatty acids exhibited increased oligomycin sensitivity and decreased 2,4-dinitrophenol-induced stimulation [240]. The authors suggested that in vivo changes in the thickness of the lipid bilayer might alter mitochondrial ATPase activity.

Studies carried out in our laboratory with a great diversity of compounds, including drugs [233,234], insecticides [241], herbicides [242] and other synthetic compounds [243,244], which exhibit high toxicity towards mitochondrial functioning, have suggested that mitochondriotoxicity is often mediated by effects exerted by the compounds on mitochondrial membrane lipids.
Thus, data gathered from biophysical studies using different technical approaches and a variety of membrane model systems showed that membrane physical properties, such as fluidity, lateral heterogeneity and curvature stress, were affected by those compounds in such a manner that adverse repercussions would be expected in mitochondrial functioning [233,234,237,243-247].

\section{Open perspectives and words of caution}

Therapies addressed to mitochondrial lipids may be successfully used in the context of mitochondrial disease and dysfunction, due to the strict association of lipids such as CL with mitochondria membrane proteins and their involvement in mitochondrial function. Recent evidence suggests membrane-lipid therapies as potentially useful by themselves or in combination with other therapies, to treat common pathologies, such as cancer, cardiovascular diseases, neurodegenerative processes, obesity, metabolic disorders, inflammation, and infectious and autoimmune diseases, but only future studies will enable determining the full potential of this novel therapeutic approach [248]. Most drugs used with pharmacological purposes have been designed to target specific membrane proteins, at relatively low concentrations. However, some of these drugs hold side pharmacological effects at higher concentrations [249]. These less specific effects towards membrane-associated proteins may arise from the interaction of lipophilic drugs with the lipid bilayer, causing changes in their structural and elastic properties, and resulting in alterations of protein distribution in the plane of the membrane and/or in alterations of protein functional conformation [249-252]. The intricate interplay between lipids and membrane protein structure and function makes it reasonable to infer that lipid bilayers may influence drug action towards membrane protein targets also at low concentrations. The disruption of membrane lipid rafts and alterations of protein distribution between raft and non-raft domains have been proposed as the means by which drugs may influence membrane protein activity with a relative specificity [253].

Considering all data mentioned above, the use of specific diets to modulate drug membrane-activity should seriously be taken into account in situations of either managing membrane-localized toxicity or potentiating treatment in a disease context. Diet manipulation may then represent a way to reduce the toxic outcomes brought by the use of some drugs or to assist their pharmacological action. Further work is necessary in order to fully appraise the potential of dietary interventions in improving the chemotherapeutic activity of pharmacological agents. In this context, membrane lipid-mediated therapeutic strategies have been proposed [248], in which the molecular targets are the lipids and the structures they form (membrane-lipid therapy). The final goal of this approach is to develop drugs able to control the activity of membrane-associated proteins by regulating membrane lipid composition and/or structure.

Finally, it is clear that CL has a very special role in the modulation of mitochondrial function at health and disease conditions, determining also the triggering of the mitochondrial pathway for apoptosis. Since it has been demonstrated that CL synthase has the unexpected role of modulating the physiology of mitochondrial membranes, increasing their resistance to metabolic stress [142], one can aim at targeting this enzyme to improve a mitochondrial disease-related phenotype. How this can be achieved or which pathologies can be targeted by this approach are questions that require further investigation. Finally, a word of caution: despite many mechanisms have been proposed implicating CL content alterations in different pathologies, this may also result from variations in the overall mitochondrial mass. This is often an overlooked aspect in many studies, in which proper internal standards (e.g., CL content/citrate synthase activity) should be used. 
Nevertheless, there is strong and clear evidence that in Barth syndrome, among other conditions, disruption of CL metabolism results in a decrease of CL mass without loss of mitochondrial content $[254,110]$. Other works, however, overlooked the determination of CL content/mitochondrial units $[136,255]$. Therefore, caution should be taken prior to infer that different conditions result in a decrease in $\mathrm{CL}$ content without ensuring that mitochondrial copy number in cells remained constant.

\section{Acknowledgements}

Work at the authors laboratory is supported by the Portuguese Foundation for Science and Technology and FEDER/COMPETE (research Grants PTDC-QUI-QUI-101409-2008; PTDC/QUI-BIQ/ 103001/2008 and Pest-C/SAU/LA0001/2013-2014). J.P.M. acknowledges FCT for Ph.D. Grant SFRH/BD/37626/2007. The funding agency had no role in the decision to publish this work.

\section{References}

[1] Sagan L. On the origin of mitosing cells. 1967. J NIH Res 1993;5:65-72.

[2] Embley TM, Martin W. Eukaryotic evolution, changes and challenges. Nature 2006;440:623-30.

[3] Mackenzie S, McIntosh L. Higher plant mitochondria. Plant Cell 1999;11:571-86.

[4] Vanlerberghe GC. Alternative oxidase: a mitochondrial respiratory pathway to maintain metabolic and signaling homeostasis during abiotic and biotic stress in plants. Int J Mol Sci 2013;14:6805-47.

[5] Millar AH, Whelan J, Soole KL, Day DA. Organization and regulation of mitochondrial respiration in plants. Annu Rev Plant Biol 2011;62:79-104.

[6] McDonald AE, Vanlerberghe GC. Origins, evolutionary history, and taxonomic distribution of alternative oxidase and plastoquinol terminal oxidase. Comp Biochem Physiol Part D Genomics Proteomics 2006;1:357-64.

[7] Kushnareva Y, Newmeyer DD. Bioenergetics and cell death. Ann NY Acad Sci 2010;1201:50-7.

[8] Mitchell P. Chemiosmotic coupling in oxidative and photosynthetic phosphorylation. Biochim Biophys Acta Bioenerg 2011;1807:1507-38.

[9] Boyer PD. The ATP synthase - a splendid molecular machine. Annu Rev Biochem 1997;66:717-49.

[10] Papa S. Mitochondrial oxidative phosphorylation changes in the life span. Molecular aspects and physiopathological implications. Biochim Biophys Acta Bioenerg 1996;1276:87-105.

[11] Duchen MR, Szabadkai G. Roles of mitochondria in human disease. Essays Biochem 2010;47:115-37.

[12] Osman C, Voelker DR, Langer T. Making heads or tails of phospholipids in mitochondria. J Cell Biol 2011:192:7-16.

[13] Stubbs CD, Smith AD. The modification of mammalian membrane polyunsaturated fatty acid composition in relation to membrane fluidity and function. Biochim Biophys Acta - Rev Biomembr 1984;779:89-137.

[14] Raison JK. The influence of temperature-induced phase changes on the kinetics of respiratory and other membrane-associated enzyme systems. J Bioenerg Biomembr 1973;4:285-309.

[15] Haeffner E, Privett $O$. Influence of dietary fatty acids on membrane properties and enzyme activities of liver mitochondria of normal and hypophysectomized rats. Lipids 1975;10:75-81.

[16] McMurchie EJ, Raison JK. Membrane lipid fluidity and its effect on the activation energy of membrane-associated enzymes. Biochim Biophys Acta Biomembr 1979;554:364-74.

[17] Innis SM, Clandinin MT. Dynamic modulation of mitochondrial innermembrane lipids in rat heart by dietary fat. Biochem J 1981;193:155-67.

[18] Innis SM, Clandinin MT. Mitochondrial-membrane polar-head-group composition is influenced by diet fat. Biochem J 1981;198:231-4.

[19] Brenner RR. Effect of unsaturated acids on membrane structure and enzyme kinetics. Prog Lipid Res 1984;23:69-96.

[20] Monteiro JP, Pereira CV, Silva AM, Maciel E, Baldeiras I, Peixoto F, et al. Rapeseed oil-rich diet alters hepatic mitochondrial membrane lipid composition and disrupts bioenergetics. Arch Toxicol 2013. in press. http:// dx.doi.org/10.1016/j.plipres.2013.06.002.

[21] Yamaoka S, Urade R, Kito M. Mitochondrial function in rats is affected by modification of membrane phospholipids with dietary sardine oil. J Nutr 1988;118:290-6.

[22] Brand MD, Couture P, Hulbert AJ. Liposomes from mammalian liver mitochondria are more polyunsaturated and leakier to protons than those from reptiles. Comp Biochem Physiol B Biochem Mol Biol 1994;108:181-8.

[23] Barzanti V, Battino M, Baracca A, Cavazzoni M, Cocchi M, Noble R, et al. The effect of dietary lipid changes on the fatty acid composition and function of liver, heart and brain mitochondria in the rat at different ages. Br J Nutr 1994;71:193-202.

[24] Brand MD, Couture P, Else PL, Withers KW, Hulbert AJ. Evolution of energy metabolism. Proton permeability of the inner membrane of liver mitochondria is greater in a mammal than in a reptile. Biochem J 1991;275:81-6.

[25] Brand MD, Chien LF, Ainscow EK, Rolfe DF, Porter RK. The causes and functions of mitochondrial proton leak. Biochim Biophys Acta 1994;1187:132-9.

[26] Brookes PS, Buckingham JA, Tenreiro AM, Hulbert AJ, Brand MD. The proton permeability of the inner membrane of liver mitochondria from ectothermic and endothermic vertebrates and from obese rats: correlations with standard metabolic rate and phospholipid fatty acid composition. Comp Biochem Physiol B Biochem Mol Biol 1998;119:325-34.

[27] Clandinin MT, Field CJ, Hargreaves K, Morson L, Zsigmond E. Role of diet fat in subcellular structure and function. Can J Physiol Pharmacol 1985;63:546-56.

[28] Dahlhoff EA, Somero GN. Effects of temperature on mitochondria from abalone (Genus haliotis): adaptative plsaticity and its limits. J Exp Biol 1993;185:151-68.

[29] Vázquez-Memije ME, Cárdenas-Méndez MJ, Tolosa A, Hafidi ME. Respiratory chain complexes and membrane fatty acids composition in rat testis mitochondria throughout development and ageing. Exp Gerontol 2005;40:482-90.

[30] Ramsey JJ, Harper M-E, Humble SJ, Koomson EK, Ram JJ, Bevilacqua L, et al. Influence of mitochondrial membrane fatty acid composition on proton leak and $\mathrm{H}_{2} \mathrm{O}_{2}$ production in liver. Comp Biochem Physiol B Biochem Mol Biol 2005;140:99-108.

[31] O'Shea KM, Khairallah RJ, Sparagna GC, Xu W, Hecker PA, Robillard-Frayne I, et al. Dietary [omega]-3 fatty acids alter cardiac mitochondrial phospholipid composition and delay $\mathrm{Ca}^{2+}$-induced permeability transition. J Mol Cell Cardiol 2009;47:819-27.

[32] Pfeiffer K, Gohil V, Stuart RA, Hunte C, Brandt U, Greenberg ML, et al Cardiolipin stabilizes respiratory chain supercomplexes. J Biol Chem 2003;278:52873-80

[33] Gonzalvez F, Gottlieb E. Cardiolipin: setting the beat of apoptosis. Apoptosis 2007;12:877-85.

[34] Claypool SM. Cardiolipin, a critical determinant of mitochondrial carrier protein assembly and function. Biochim Biophys Acta Biomembr 2009;1788:2059-68.

[35] Wahle KWJ. Fatty acid modification and membrane lipids. Proc Nutr Soc 1983;42:273-87.

[36] Gohil VM, Greenberg ML. Mitochondrial membrane biogenesis: phospholipids and proteins go hand in hand. J Cell Biol 2009;184:469-72.

[37] Huang Z, Jiang J, Tyurin VA, Zhao Q, Mnuskin A, Ren J, et al. Cardiolipin deficiency leads to decreased cardiolipin peroxidation and increased resistance of cells to apoptosis. Free Radic Biol Med 2008;44:1935-44.

[38] Jiang F, Rizavi HS, Greenberg ML. Cardiolipin is not essential for the growth of Saccharomyces cerevisiae on fermentable or non-fermentable carbon sources. Mol Microbiol 1997;26:481-91.

[39] Ohtsuka T, Nishijima M, Akamatsu Y. A somatic cell mutant defective in phosphatidylglycerophosphate synthase, with impaired phosphatidylglycerol and cardiolipin biosynthesis. J Biol Chem 1993;268:22908-13.

[40] Nadal-Casellas A, Amengual-Cladera E, Proenza AM, Llado I, Gianotti M. Longterm high-fat-diet feeding impairs mitochondrial biogenesis in liver of male and female rats. Cell Physiol Biochem 2010;26:291-302.

[41] Kien CL. Dietary interventions for metabolic syndrome: role of modifying dietary fats. Curr Diab Rep 2009;9:43-50.

[42] Igney $\mathrm{FH}$, Krammer $\mathrm{PH}$. Death and anti-death: tumour resistance to apoptosis. Nat Rev Cancer 2002;2:277-88.

[43] Danial NN, Korsmeyer SJ. Cell death: critical control points. Cell 2004;116:205-19.

[44] Kroemer G, Galluzzi L, Brenner C. Mitochondrial membrane permeabilization in cell death. Physiol Rev 2007;87:99-163.

[45] Bernardi P, Krauskopf A, Basso E, Petronilli V, Blalchy-Dyson E, Di Lisa F, et al The mitochondrial permeability transition from in vitro artifact to disease target. FEBS J 2006;273:2077-99.

[46] Skulachev V. Bioenergetic aspects of apoptosis, necrosis and mitoptosis Apoptosis 2006;11:473-85.

[47] Scaffidi P, Misteli T, Bianchi ME. Release of chromatin protein HMGB1 by necrotic cells triggers inflammation. Nature 2002;418:191-5.

[48] Crimi M, Esposti MD. Apoptosis-induced changes in mitochondrial lipids. Biochim Biophys Acta Mol Cell Res 2011;1813:551-7.

[49] Degli Esposti M, Cristea IM, Gaskell SJ, Nakao Y, Dive C. Proapoptotic Bid binds to monolysocardiolipin, a new molecular connection between mitochondrial membranes and cell death. Cell Death Differ 2003;10:1300-9.

[50] Cristea IM, Degli Esposti M. Membrane lipids and cell death: an overview. Chem Phys Lipids 2004;129:133-60.

[51] Kagan VE, Bayir A, Bayir H, Stoyanovsky D, Borisenko GG, Tyurina YY, et al Mitochondria-targeted disruptors and inhibitors of cytochrome c/cardiolipin peroxidase complexes: a new strategy in anti-apoptotic drug discovery. Mol Nutr Food Res 2009;53:104-14.

[52] Kagan VE, Tyurin VA, Jiang J, Tyurina YY, Ritov VB, Amoscato AA, et al. Cytochrome $\mathrm{c}$ acts as a cardiolipin oxygenase required for release of proapoptotic factors. Nat Chem Biol 2005;1:223-32.

[53] Kagan VE, Bayir HA, Belikova NA, Kapralov O, Tyurina YY, Tyurin VA, et al Cytochrome c/cardiolipin relations in mitochondria: a kiss of death. Free Radic Biol Med 2009;46:1439-53.

[54] Basova LV, Kurnikov IV, Wang L, Ritov VB, Belikova NA, Vlasova II, et al. Cardiolipin switch in mitochondria: shutting off the reduction of cytochrome c and turning on the peroxidase activity. Biochemistry 2007;46:3423-34. 
[55] Gonzalvez F, Gottlieb E. Cardiolipin: setting the beat of apoptosis. Apoptosis 2007:12:877-85

[56] Sorice M, Manganelli V, Matarrese P, Tinari A, Misasi R, Malorni W, et al. Cardiolipin-enriched raft-like microdomains are essential activating platforms for apoptotic signals on mitochondria. FEBS Lett 2009;583:2447-50.

[57] Gault CR, Obeid LM, Hannun YA. An overview of sphingolipid metabolism: from synthesis to breakdown. Adv Exp Med Biol 2010;688:1-23.

[58] Bionda C, Portoukalian J, Schmitt D, Rodriguez-Lafrasse C, Ardail D. Subcellular compartmentalization of ceramide metabolism: MAM (mitochondria-associated membrane) and/or mitochondria? Biochem J 2004;382:527-33.

[59] Siskind LJ. Mitochondrial ceramide and the induction of apoptosis. J Bioenerg Biomembr 2005;37:143-53.

[60] Siskind LJ, Kolesnick RN, Colombini M. Ceramide forms channels in mitochondrial outer membranes at physiologically relevant concentrations. Mitochondrion 2006;6:118-25.

[61] Lee H, Rotolo JA, Mesicek J, Penate-Medina T, Rimner A, Liao W-C, et al. Mitochondrial ceramide-rich macrodomains functionalize Bax upon irradiation. PLoS One 2011;6:e19783.

[62] Silva L, de Almeida RF, Fedorov A, Matos AP, Prieto M. Ceramide-platform formation and -induced biophysical changes in a fluid phospholipid membrane. Mol Membr Biol 2006;23:137-48.

[63] Grassme H, Riethmuller J, Gulbins E. Biological aspects of ceramide-enriched membrane domains. Prog Lipid Res 2007;46:161-70.

[64] Chipuk JE, McStay GP, Bharti A, Kuwana T, Clarke CJ, Siskind LJ, et al Sphingolipid metabolism cooperates with BAK and BAX to promote the mitochondrial pathway of apoptosis. Cell 2012;148:988-1000.

[65] Sorice M, Matarrese P, Tinari A, Giammarioli AM, Garofalo T, Manganelli V, et al. Raft component GD3 associates with tubulin following CD95/Fas ligation. FASEB J 2009;23:3298-308.

[66] Garofalo T, Giammarioli AM, Misasi R, Tinari A, Manganelli V, Gambardella L, et al. Lipid microdomains contribute to apoptosis-associated modifications of mitochondria in T cells. Cell Death Differ 2005;12:1378-89.

[67] Pike LJ. The challenge of lipid rafts. J Lipid Res 2009;50:S323-8.

[68] Malorni W, Giammarioli A, Garofalo T, Sorice M. Dynamics of lipid raft components during lymphocyte apoptosis: the paradigmatic role of GD3. Apoptosis 2007;12:941-9.

[69] Verhagen AM, Ekert PG, Pakusch M, Silke J, Connolly LM, Reid GE, et al. Identification of DIABLO, a mammalian protein that promotes apoptosis by binding to and antagonizing IAP proteins. Cell 2000;102:43-53.

[70] Warburg O. On the origin of cancer cells. Science 1956;123:309-14.

[71] Barbosa IA, Machado NG, Skildum AJ, Scott PM, Oliveira PJ. Mitochondrial remodeling in cancer metabolism and survival: potential for new therapies. Biochim Biophys Acta 2012;1826:238-54.

[72] Galluzzi L, Morselli E, Kepp O, Vitale I, Rigoni A, Vacchelli E, et al Mitochondrial gateways to cancer. Mol Aspects Med 2010;31:1-20.

[73] Modica-Napolitano JS, Kulawiec M, Singh KK. Mitochondria and human cancer. Curr Mol Med 2007;7:121-31.

[74] Baggetto LG, Testa-Parussini R. Role of acetoin on the regulation of intermediate metabolism of Ehrlich ascites tumor mitochondria: its contribution to membrane cholesterol enrichment modifying passive proton permeability. Arch Biochem Biophys 1990;283:241-8.

[75] Montero J, Morales A, Llacuna L, Lluis JM, Terrones O, Basanez G, et al. Mitochondrial cholesterol contributes to chemotherapy resistance in hepatocellular carcinoma. Cancer Res 2008;68:5246-56.

[76] Campbell AM, Capuano A, Chan SH. A cholesterol-binding and transporting protein from rat liver mitochondria. Biochim Biophys Acta 2002;1567:123-32.

[77] Kiebish MA, Han X, Cheng H, Chuang JH, Seyfried TN. Cardiolipin and electron transport chain abnormalities in mouse brain tumor mitochondria: lipidomic evidence supporting the Warburg theory of cancer. J Lipid Res 2008;49:2545-56.

[78] Kiebish MA, Han X, Cheng H, Seyfried TN. In vitro growth environment produces lipidomic and electron transport chain abnormalities in mitochondria from non-tumorigenic astrocytes and brain tumours. ASN Neuro 2009;1(3): pii: e00011.

[79] Morton R, Cunningham C, Jester R, Waite M, Miller N, Morris HP. Alteration of mitochondrial function and lipid composition in Morris 7777 hepatoma. Cancer Res 1976;36:3246-54.

[80] Lopez-Rios F, Sanchez-Arago M, Garcia-Garcia E, Ortega AD, Berrendero JR, Pozo-Rodriguez $\mathrm{F}$, et al. Loss of the mitochondrial bioenergetic capacity underlies the glucose avidity of carcinomas. Cancer Res 2007;67:9013-7.

[81] Kim HK, Park WS, Kang SH, Warda M, Kim N, Ko JH, et al. Mitochondrial alterations in human gastric carcinoma cell line. Am J Physiol Cell Physio 2007;293:C761-71.

[82] Weinberg F, Hamanaka R, Wheaton WW, Weinberg S, Joseph J, Lopez $\mathrm{M}$, et al. Mitochondrial metabolism and ROS generation are essentia for Kras-mediated tumorigenicity. Proc Natl Acad Sci USA 2010;107:8788-93.

[83] Calvani M, Comito G, Giannoni E, Chiarugi P. Time-dependent stabilization of hypoxia inducible factor-1alpha by different intracellular sources of reactive oxygen species. PLoS One 2012;7:e38388.

[84] Sanchez-Cenizo L, Formentini L, Aldea M, Ortega AD, Garcia-Huerta P, Sanchez-Arago $\mathrm{M}$, et al. Up-regulation of the ATPase inhibitory factor (IF1) of the mitochondrial H+-ATP synthase in human tumors mediates the metabolic shift of cancer cells to a Warburg phenotype. J Biol Chem 2010;285:25308-13.

[85] Ho PW, Ho JW, Tse HM, So DH, Yiu DC, Liu HF, et al. Uncoupling protein-4 (UCP4) increases ATP supply by interacting with mitochondrial Complex II in neuroblastoma cells. PLoS One 2012;7:e32810.

[86] Robbins D, Zhao Y. New aspects of mitochondrial uncoupling proteins (UCPs) and their roles in tumorigenesis. Int J Mol Sci 2011;12:5285-93.

87] Ayyasamy V, Owens KM, Desouki MM, Liang P, Bakin A, Thangaraj K, et al. Cellular model of Warburg effect identifies tumor promoting function of UCP2 in breast cancer and its suppression by genipin. PLoS One 2011;6:e24792.

[88] Campbell AM, Chan SH. Mitochondrial membrane cholesterol, the voltage dependent anion channel (VDAC), and the Warburg effect. J Bioenerg Biomembr 2008;40:193-7.

[89] Bosch M, Mari M, Herms A, Fernandez A, Fajardo A, Kassan A, et al. Caveolin-1 deficiency causes cholesterol-dependent mitochondrial dysfunction and apoptotic susceptibility. Curr Biol 2011;21:681-6.

[90] Friedrich T, Richter B, Gaiser T, Weiss C, Janssen KP, Einwaechter H, et al. Deficiency of caveolin-1 in Apcmin/+ mice promotes colorectal tumorigenesis. Carcinogenesis 2013. in press. http://dx.doi.org/10.1093/ carcin/bgt142.

[91] Sotgia F, Del Galdo F, Casimiro MC, Bonuccelli G, Mercier I, Whitaker-Menezes $\mathrm{D}$, et al. Caveolin-1 ${ }^{-1-}$ null mammary stromal fibroblasts share characteristics with human breast cancer-associated fibroblasts. Am J Pathol 2009;174: 746-61.

92] Bonuccelli G, Whitaker-Menezes D Castello-Cros R, Pavlides S, Pestell RG Fatatis A, et al. The reverse Warburg effect: glycolysis inhibitors prevent the tumor promoting effects of caveolin-1 deficient cancer associated fibroblasts. Cell Cycle 2010;9:1960-71.

[93] Jahnke VE, Sabido O, Defour A, Castells J, Lefai E, Roussel D, et al. Evidence for mitochondrial respiratory deficiency in rat rhabdomyosarcoma cells. PLoS One 2010;5:e8637.

[94] Dumas JF, Goupille C, Julienne CM, Pinault M, Chevalier S, Bougnoux P, et al. Efficiency of oxidative phosphorylation in liver mitochondria is decreased in a rat model of peritoneal carcinosis. J Hepatol 2011;54:320-7.

[95] Kiebish MA, Han X, Cheng H, Chuang JH, Seyfried TN. Brain mitochondrial lipid abnormalities in mice susceptible to spontaneous gliomas. Lipids 2008;43:951-9.

[96] Todor IN, Lukyanova NY, Chekhun VF. The lipid content of cisplatin- and doxorubicin-resistant MCF-7 human breast cancer cells. Exp Oncol 2012;34:97-100.

[97] Choi SY, Gonzalvez F, Jenkins GM, Slomianny C, Chretien D, Arnoult D, et al. Cardiolipin deficiency releases cytochrome $\mathrm{c}$ from the inner mitochondrial membrane and accelerates stimuli-elicited apoptosis. Cell Death Differ 2007; $14: 597-606$.

[98] Ostrander DB, Sparagna GC, Amoscato AA, McMillin JB, Dowhan W. Decreased cardiolipin synthesis corresponds with cytochrome c release in palmitateinduced cardiomyocyte apoptosis. J Biol Chem 2001;276:38061-7.

[99] Abel F, Sjoberg RM, Nilsson S, Kogner P, Martinsson T. Imbalance of the mitochondrial pro- and anti-apoptotic mediators in neuroblastoma tumours with unfavourable biology. Eur J Cancer 2005;41:635-46.

[100] Kurtoglu M, Lampidis TJ. From delocalized lipophilic cations to hypoxia: blocking tumor cell mitochondrial function leads to therapeutic gain with glycolytic inhibitors. Mol Nutr Food Res 2009;53:68-75.

[101] Jones LW, Narayan KS, Shapiro CE, Sweatman TW. Rhodamine-123: therapy for hormone refractory prostate cancer, a phase I clinical trial. J Chemother 2005; $17: 435-40$.

[102] Modica-Napolitano JS, Aprille JR. Delocalized lipophilic cations selectively target the mitochondria of carcinoma cells. Adv Drug Deliv Rev 2001;49:63-70.

[103] Powers SK, Ellington K. Selective retention of rhodamine-123 by malignant glioma in the rat. J Neurooncol 1988;6:343-7.

[104] Chunta JL, Vistisen KS, Yazdi Z, Braun RD. Uptake rate of cationic mitochondrial inhibitor MKT-077 determines cellular oxygen consumption change in carcinoma cells. PLoS One 2012;7:e37471.

[105] Propper DJ, Braybrooke JP, Taylor DJ, Lodi R, Styles P, Cramer JA, et al. Phase I trial of the selective mitochondrial toxin MKT077 in chemo-resistant solid tumours. Ann Oncol 1999;10:923-7.

[106] Lampidis TJ, Hasin Y, Weiss MJ, Chen LB. Selective killing of carcinoma cells "in vitro" by lipophilic-cationic compounds: a cellular basis. Biomed Pharmacother 1985;39:220-6.

[107] Pereira GC, Branco AF, Matos JA, Pereira SL, Parke D, Perkins EL, et al Mitochondrially targeted effects of berberine [Natural Yellow 18, 5,6dihydro-9,10-dimethoxybenzo(g)-1,3-benzodioxolo(5,6-a) quinolizinium] on K1735-M2 mouse melanoma cells: comparison with direct effects on isolated mitochondrial fractions. J Pharmacol Exp Ther 2007;323:636-49.

[108] Serafim TL, Oliveira PJ, Sardao VA, Perkins E, Parke D, Holy J. Different concentrations of berberine result in distinct cellular localization patterns and cell cycle effects in a melanoma cell line. Cancer Chemother Pharmacol 2008;61:1007-18

[109] Gogvadze V, Orrenius S, Zhivotovsky B. Mitochondria in cancer cells: what is so special about them? Trends Cell Biol 2008;18:165-73.

[110] Chicco AJ, Sparagna GC. Role of cardiolipin alterations in mitochondrial dysfunction and disease. Am J Physiol Cell Physiol 2007;292:C33-44.

[111] Schlame M, Ren M. Barth syndrome, a human disorder of cardiolipin metabolism. FEBS Lett 2006;580:5450-5. 
[112] Mancuso DJ, Sims HF, Han X, Jenkins CM, Guan SP, Yang K, et al. Genetic ablation of calcium-independent phospholipase A2-gamma leads to alterations in mitochondrial lipid metabolism and function resulting in a deficient mitochondrial bioenergetic phenotype. J Biol Chem 2007;282:34611-22.

[113] Paradies G, Petrosillo G, Pistolese M, Ruggiero FM. The effect of reactive oxygen species generated from the mitochondrial electron transport chain on the cytochrome c oxidase activity and on the cardiolipin content in bovine heart submitochondrial particles. FEBS Lett 2000;466:323-6.

[114] Petrosillo G, Di Venosa N, Ruggiero FM, Pistolese M, D’Agostino D, Tiravanti E, et al. Mitochondrial dysfunction associated with cardiac ischemia/ reperfusion can be attenuated by oxygen tension control. Role of oxygenfree radicals and cardiolipin. Biochim Biophys Acta Bioenerg 2005;1710:78-86.

[115] Sparagna GC, Chicco AJ, Murphy RC, Bristow MR, Johnson CA, Rees ML, et al. Loss of cardiac tetralinoleoyl cardiolipin in human and experimental heart failure. J Lipid Res 2007;48:1559-70.

[116] Bione S, D’Adamo P, Maestrini E, Gedeon AK, Bolhuis PA, Toniolo D. A novel Xlinked gene, G4.5. is responsible for Barth syndrome. Nat Genet $1996 ; 12: 385-9$

[117] Schlame M, Kelley RI, Feigenbaum A, Towbin JA, Heerdt PM, Schieble T, et al. Phospholipid abnormalities in children with Barth syndrome. J Am Coll Cardiol 2003:42:1994-9.

[118] Barth PG, Valianpour F, Bowen VM, Lam J, Duran M, Vaz FM, et al. X-linked cardioskeletal myopathy and neutropenia (Barth syndrome): an update. Am J Med Genet A 2004;126A:349-54.

[119] Kelley RI, Cheatham JP, Clark BJ, Nigro MA, Powell BR, Sherwood GW, et al. Xlinked dilated cardiomyopathy with neutropenia, growth retardation, and 3methylglutaconic aciduria. J Pediatr 1991;119:738-47.

[120] Barth PG, Scholte HR, Berden JA, Van der Klei-Van Moorsel JM, Luyt-Houwen IE, Van 't Veer-Korthof ET, et al. An X-linked mitochondrial disease affecting cardiac muscle, skeletal muscle and neutrophil leucocytes. J Neurol Sci 1983;62:327-55.

[121] Neuwald AF. Barth syndrome may be due to an acyltransferase deficiency. Curr Biol 1997; 7:R465-6.

[122] Xu Y, Sutachan JJ, Plesken H, Kelley RI, Schlame M. Characterization of lymphoblast mitochondria from patients with Barth syndrome. Lab Invest 2005;85:823-30.

[123] Barth PG, Van den Bogert C, Bolhuis PA, Scholte HR, van Gennip AH, Schutgens RB, et al. X-linked cardioskeletal myopathy and neutropenia (Barth syndrome): respiratory-chain abnormalities in cultured fibroblasts. J Inherit Metab Dis 1996;19:157-60.

[124] Claypool SM. Cardiolipin, a critical determinant of mitochondrial carrier protein assembly and function. Biochim Biophys Acta 2009;1788:2059-68.

[125] Vreken P, Valianpour F, Nijtmans LG, Grivell LA, Plecko B, Wanders RJ, et al. Defective remodeling of cardiolipin and phosphatidylglycerol in Barth syndrome. Biochem Biophys Res Commun 2000;279:378-82.

[126] Schlame M, Towbin JA, Heerdt PM, Jehle R, DiMauro S, Blanck TJ. Deficiency of tetralinoleoyl-cardiolipin in Barth syndrome. Ann Neurol 2002;51:634-7.

[127] Schlame M. Cardiolipin synthesis for the assembly of bacterial and mitochondrial membranes. J Lipid Res 2008;49:1607-20.

[128] Steward CG, Newbury-Ecob RA, Hastings R, Smithson SF, Tsai-Goodman B, Quarrell OW, et al. Barth syndrome: an X-linked cause of fetal cardiomyopathy and stillbirth. Prenat Diagn 2010;30:970-6.

[129] Malhotra A, Edelman-Novemsky I, Xu Y, Plesken H, Ma J, Schlame M, et al. Role of calcium-independent phospholipase A2 in the pathogenesis of Barth syndrome. Proc Natl Acad Sci USA 2009;106:2337-41.

[130] Schlame M, Acehan D, Berno B, Xu Y, Valvo S, Ren M, et al. The physical state of lipid substrates provides transacylation specificity for tafazzin. Nat Chem Biol 2012;8:862-9.

[131] Malhotra A, Xu Y, Ren M, Schlame M. Formation of molecular species of mitochondrial cardiolipin. 1. A novel transacylation mechanism to shuttle fatty acids between sn- 1 and sn-2 positions of multiple phospholipid species. Biochim Biophys Acta 2009;1791:314-20.

[132] Xu Y, Malhotra A, Ren M, Schlame M. The enzymatic function of tafazzin. J Biol Chem 2006;281:39217-24.

[133] Schlame M. Cardiolipin remodeling and the function of tafazzin. Biochim Biophys Acta 2013;1831:582-8.

[134] Tolěkis AI, Dagis AI, Prashkiavichius AK. Effect of myocardial ischemia on the phospholipid composition of cardiac tissue and mitochondria. Vopr Med Khim 1982;28:64-7.

[135] Vasdev SC, Biro GP, Narbaitz R, Kako KJ. Membrane changes induced by early myocardial ischemia in the dog. Can J Biochem 1980;58:1112-29.

[136] Chen Q Lesnefsky EJ. Depletion of cardiolipin and cytochrome c during ischemia increases hydrogen peroxide production from the electron transport chain. Free Radic Biol Med 2006;40(6):976-82.

[137] O'Rourke B, Reibel DK. Effects of adrenoceptor blockade on cardiac hypertrophy and myocardial phospholipids. Proc Soc Exp Biol Med 1992;200:95-100.

[138] Reibel DK, O'Rourke B, Foster KA, Hutchinson H, Uboh CE, Kent RL. Altered phospholipid metabolism in pressure-overload hypertrophied hearts. Am J Physiol Heart Circ Physiol 1986;250:H1-6.

[139] Okumura K, Yamada Y, Kondo J, Hashimoto H, Ito T, Kitoh J. Decreased 1,2-diacylglycerol levels in myopathic hamster hearts during the development of heart failure. J Mol Cell Cardiol 1991;23:409-16.
[140] Sparagna GC, Lesnefsky EJ. Cardiolipin remodeling in the heart. J Cardiovasc Pharmacol 2009;53:290-301.

[141] Han X, Yang J, Cheng H, Yang K, Abendschein DR, Gross RW. Shotgun lipidomics identifies cardiolipin depletion in diabetic myocardium linking altered substrate utilization with mitochondrial dysfunction. Biochemistry 2005;44:16684-94.

[142] Kiebish MA, Yang K, Sims HF, Jenkins CM, Liu X, Mancuso DJ, et al. Myocardial regulation of lipidomic flux by cardiolipin synthase: setting the beat for bioenergetic efficiency. J Biol Chem 2012;287:25086-97.

[143] Paradies G, Ruggiero FM, Petrosillo G, Quagliariello E. Stimulation of carnitine acylcarnitine translocase activity in heart mitochondria from hyperthyroid rats. FEBS Lett 1996;397:260-2.

[144] Cao SG, Cheng P, Angel A, Hatch GM. Thyroxine stimulates phosphatidylglycerolphosphate synthase activity in rat heart mitochondria. Biochim Biophys Acta 1995;1256:241-4.

[145] Paradies G, Ruggiero FM. Effect of hyperthyroidism on the transport of pyruvate in rat-heart mitochondria. Biochim Biophys Acta Bioenerg 1988;935:79-86.

[146] Paradies G, Ruggiero FM. Stimulation of phosphate transport in rat-liver mitochondria by thyroid hormones. Biochim Biophys Acta Bioenerg 1990;1019:133-6.

[147] Taylor W, Xu F, Ma B, Mutter T, Dolinsky V, Hatch G. Expression of monolysocardiolipin acyltransferase activity is regulated in concert with the level of cardiolipin and cardiolipin biosynthesis in the mammalian heart BMC Biochem 2002;3:9.

[148] Petrosillo G, Portincasa P, Grattagliano I, Casanova G, Matera M, Ruggiero FM et al. Mitochondrial dysfunction in rat with nonalcoholic fatty liver: involvement of complex I, reactive oxygen species and cardiolipin. Biochim Biophys Acta Bioenerg 2007:1767:1260-7.

[149] Ellis CE, Murphy EJ, Mitchell DC, Golovko MY, Scaglia F, Barcelo-Coblijn GC et al. Mitochondrial lipid abnormality and electron transport chain impairment in mice lacking alpha-synuclein. Mol Cell Biol 2005;25:10190-201.

150] Lucia S, Esposito M, Rossi Fanelli F, Muscaritoli M. Cancer cachexia: from molecular mechanisms to patient's care. Crit Rev Oncog 2012;17:315-21.

151] Dumas JF, Peyta L, Couet C, Servais S. Implication of liver cardiolipins in mitochondrial energy metabolism disorder in cancer cachexia. Biochimie 2013;95:27-32.

[152] Pereira GC, Pereira SP, Pereira CV, Lumini JA, Magalhaes J, Ascensao A, et al Mitochondrionopathy phenotype in doxorubicin-treated Wistar rats depends on treatment protocol and is cardiac-specific. PLoS One 2012;7:e38867.

[153] Pereira GC, Silva AM, Diogo CV, Carvalho FS, Monteiro P, Oliveira PJ. Druginduced cardiac mitochondrial toxicity and protection: from doxorubicin to carvedilol. Curr Pharm Des 2011:17:2113-29.

[154] Wallace KB. Adriamycin-induced interference with cardiac mitochondrial calcium homeostasis. Cardiovasc Toxicol 2007;7:101-7.

[155] Demant EJ. Inactivation of cytochrome c oxidase activity in mitochondria membranes during redox cycling of doxorubicin. Biochem Pharmacol 1991;41:543-52

[156] Kashfi K, Israel M, Sweatman TW, Seshadri R, Cook GA. Inhibition of mitochondrial carnitine palmitoyltransferases by adriamycin and adriamycin analogues. Biochem Pharmacol 1990;40:1441-8.

[157] Nicolay K, de Kruijff B. Effects of adriamycin on respiratory chain activities in mitochondria from rat liver, rat heart and bovine heart. Evidence for a preferential inhibition of complex III and IV. Biochim Biophys Acta 1987;892:320-30.

[158] Goormaghtigh E, Pollakis G, Ruysschaert JM. Mitochondrial membrane modifications induced by adriamycin-mediated electron transport. Biochem Pharmacol 1983;32:889-93.

[159] Goormaghtigh E, Brasseur R, Ruysschaert JM. Adriamycin inactivates cytochrome c oxidase by exclusion of the enzyme from its cardiolipin essential environment. Biochem Biophys Res Commun 1982;104:314-20.

[160] Goormaghtigh E, Chatelain P, Caspers J, Ruysschaert JM. Evidence of a complex between adriamycin derivatives and cardiolipin: possible role in cardiotoxicity. Biochem Pharmacol 1980;29:3003-10.

[161] Melo T, Videira RA, Andre S, Maciel E, Francisco CS, Oliveira-Campos AM, et al Tacrine and its analogues impair mitochondrial function and bioenergetics: a lipidomic analysis in rat brain. J Neurochem 2012;120:998-1013.

[162] Monteiro JP, Martins AF, Lucio M, Reis S, Pinheiro TJ, Geraldes CF, et al Nimesulide interaction with membrane model systems: are membrane physical effects involved in nimesulide mitochondrial toxicity? Toxicol In Vitro 2011;25:1215-23.

[163] Monteiro JP, Martins AF, Lucio M, Reis S, Geraldes CF, Oliveira PJ, et al Interaction of carbonylcyanide p-trifluoromethoxyphenylhydrazone (FCCP) with lipid membrane systems: a biophysical approach with relevance to mitochondrial uncoupling. J Bioenerg Biomembr 2011;43:287-98.

[164] Monteiro JP, Martins AF, Nunes C, Morais CM, Lucio M, Reis S, et al. A biophysical approach to menadione membrane interactions: relevance for menadione-induced mitochondria dysfunction and related deleterious therapeutic effects. Biochim Biophys Acta 2013;1828:1899-908.

[165] Garcia-Ruiz C, Mari M, Colell A, Morales A, Caballero F, Montero J, et al. Mitochondrial cholesterol in health and disease. Histol Histopathol 2009;24:117-32.

[166] Schon EA, Area-Gomez E. Mitochondria-associated ER membranes in Alzheimer disease. Mol Cell Neurosci 2013;55. 26-26. 
[167] Hayashi T, Rizzuto R, Hajnoczky G, Su TP. MAM: more than just a housekeeper. Trends Cell Biol 2009;19:81-8.

[168] Winkler E, Kamp F, Scheuring J, Ebke A, Fukumori A, Steiner H. Generation of Alzheimer disease-associated amyloid beta42/43 peptide by gammasecretase can be inhibited directly by modulation of membrane thickness. J Biol Chem 2012;287:21326-34.

[169] Fujimoto M, Hayashi T, Su TP. The role of cholesterol in the association of endoplasmic reticulum membranes with mitochondria. Biochem Biophys Res Commun 2012;417:635-9.

[170] Frank PG, Cheung MW, Pavlides S, Llaverias G, Park DS, Lisanti MP. Caveolin-1 and regulation of cellular cholesterol homeostasis. Am J Physiol Heart Circ Physiol 2006;291:H677-86.

[171] Bosch M, Mari M, Gross SP, Fernandez-Checa JC, Pol A. Mitochondrial cholesterol: a connection between caveolin, metabolism, and disease. Traffic 2011;12:1483-9.

[172] Harman D. Aging: a theory based on free radical and radiation chemistry. J Gerontol 1956;11:298-300.

[173] Loeb LA, Wallace DC, Martin GM. The mitochondrial theory of aging and its relationship to reactive oxygen species damage and somatic mtDNA mutations. Proc Natl Acad Sci USA 2005;102:18769-70.

[174] Salvioli S, Bonafe M, Capri M, Monti D, Franceschi C. Mitochondria, aging and longevity - a new perspective. FEBS Lett 2001;492:9-13.

[175] Shen J, Tower J. Programmed cell death and apoptosis in aging and life span regulation. Discov Med 2009;8:223-6.

[176] Pamplona R, Barja G, Portero-Otin M. Membrane fatty acid unsaturation, protection against oxidative stress, and maximum life span: a homeoviscouslongevity adaptation? Ann NY Acad Sci 2002;959:475-90.

[177] Gredilla R, Barja G. Minireview: the role of oxidative stress in relation to caloric restriction and longevity. Endocrinology 2005;146:3713-7.

[178] Wanagat J, Allison DB, Weindruch R. Caloric intake and aging: mechanisms in rodents and a study in nonhuman primates. Toxicol Sci 1999;52:35-40.

[179] Yu BP, Lim BO, Sugano M. Dietary restriction downregulates free radical and lipid peroxide production: plausible mechanism for elongation of life span. J Nutr Sci Vitaminol (Tokyo) 2002;48:257-64

[180] Lee J, Yu BP, Herlihy JT. Modulation of cardiac mitochondrial membrane fluidity by age and calorie intake. Free Radic Biol Med 1999;26:260-5.

[181] Venkatraman J, Fernandes G. Modulation of age-related alterations in membrane composition and receptor-associated immune functions by food restriction in Fischer 344 rats. Mech Ageing Dev 1992;63:27-44.

[182] Tacconi MT, Lligona L, Salmona M, Pitsikas N, Algeri S. Aging and food restriction: effect on lipids of cerebral cortex. Neurobiol Aging 1991;12:55-9.

[183] Ames BN, Shigenaga MK, Hagen TM. Mitochondrial decay in aging. Biochim Biophys Acta 1995;1271:165-70.

[184] Beyer K, Klingenberg M. ADP/ATP carrier protein from beef heart mitochondria has high amounts of tightly bound cardiolipin, as revealed by 31P nuclear magnetic resonance. Biochemistry 1985;24:3821-6.

[185] Bisaccia F, De Palma A, Prezioso G, Palmieri F. Kinetic characterization of the reconstituted tricarboxylate carrier from rat liver mitochondria. Biochim Biophys Acta 1990;1019:250-6.

[186] Bisaccia F, Palmieri F. Specific elution from hydroxylapatite of the mitochondrial phosphate carrier by cardiolipin. Biochim Biophys Acta Bioenerg 1984;766:386-94.

[187] Sharpley MS, Shannon RJ, Draghi F, Hirst J. Interactions between phospholipids and NADH: ubiquinone oxidoreductase (complex I) from bovine mitochondria. Biochemistry 2005;45:241-8.

[188] Lange C, Nett JH, Trumpower BL, Hunte C. Specific roles of proteinphospholipid interactions in the yeast cytochrome bc1 complex structure. EMBO J 2001;20:6591-600.

[189] Shinzawa-Itoh K, Aoyama H, Muramoto K, Terada H, Kurauchi T, Tadehara Y, et al. Structures and physiological roles of 13 integral lipids of bovine heart cytochrome c oxidase. EMBO J 2007;26:1713-25.

[190] Fry M, Green DE. Cardiolipin requirement for electron transfer in complex I and III of the mitochondrial respiratory chain. $J$ Biol Chem 1981;256:1874-80.

[191] Robinson NC. Functional binding of cardiolipin to cytochrome c oxidase. J Bioenerg Biomembr 1993;25:153-63.

[192] Zhang M, Mileykovskaya E, Dowhan W. Cardiolipin is essential for organization of complexes III and IV into a supercomplex in intact yeast mitochondria. J Biol Chem 2005;280:29403-8.

[193] Schägger H. Respiratory chain supercomplexes of mitochondria and bacteria. Biochim Biophys Acta - Bioenerg 2002;1555:154-9.

[194] Ames BN, Liu J. Delaying the mitochondrial decay of aging with acetylcarnitine. Ann NY Acad Sci 2004;1033:108-16.

[195] Paradies G, Ruggiero FM. Age-related changes in the activity of the pyruvate carrier and in the lipid composition in rat-heart mitochondria. Biochim Biophys Acta 1990;1016:207-12.

[196] Petrosillo G, De Benedictis V, Ruggiero FM, Paradies G. Decline in cytochrome c oxidase activity in rat-brain mitochondria with aging. Role of peroxidized cardiolipin and beneficial effect of melatonin. J Bioenerg Biomembr 2013.

[197] Pepe S, Tsuchiya N, Lakatta EG, Hansford RG. PUFA and aging modulate cardiac mitochondrial membrane lipid composition and $\mathrm{Ca}^{2+}$ activation of PDH. Am J Physiol Heart Circ Physiol 1999;276:H149-58.

[198] Maftah A, Ratinaud MH, Dumas M, Bonte F, Meybeck A, Julien R. Human epidermal cells progressively lose their cardiolipins during ageing without change in mitochondrial transmembrane potential. Mech Ageing Dev 1994;77:83-96.
[199] Paradies G, Ruggiero FM, Gadaleta MN, Quagliariello E. The effect of aging and acetyl-L-carnitine on the activity of the phosphate carrier and on the phospholipid composition in rat heart mitochondria. Biochim Biophys Acta 1992;1103:324-6.

[200] Paradies G, Ruggiero FM, Petrosillo G, Gadaleta MN, Quagliariello E. Effect of aging and acetyl-L-carnitine on the activity of cytochrome oxidase and adenine nucleotide translocase in rat heart mitochondria. FEBS Lett 1994;350:213-5.

[201] Paradies G, Ruggiero FM, Petrosillo G, Gadaleta MN, Quagliariello E. Carnitine-acylcarnitine translocase activity in cardiac mitochondria from aged rats: the effect of acetyl-L-carnitine. Mech Ageing Dev 1995;84: 103-12.

[202] Paradies G, Petrosillo G, Gadaleta MN, Ruggiero FM. The effect of aging and acetyl-L-carnitine on the pyruvate transport and oxidation in rat heart mitochondria. FEBS Lett 1999;454:207-9.

[203] Moghaddas S, Stoll MS, Minkler PE, Salomon RG, Hoppel CL, Lesnefsky EJ. Preservation of cardiolipin content during aging in rat heart interfibrillar mitochondria. J Gerontol A Biol Sci Med Sci 2002;57:B22-8.

[204] Lewin MB, Timiras PS. Lipid changes with aging in cardiac mitochondrial membranes. Mech Ageing Dev 1984;24:343-51.

[205] Lee HJ, Mayette J, Rapoport SI, Bazinet RP. Selective remodeling of cardiolipin fatty acids in the aged rat heart. Lipids Health Dis 2006;5:2.

[206] Paradies G, Ruggiero FM, Petrosillo G, Quagliariello E. Age-dependent decrease in the cytochrome $c$ oxidase activity and changes in phospholipids in rat-heart mitochondria. Arch Gerontol Geriatr 1993:16:263-72.

[207] Vorbeck ML, Martin AP, Long Jr JW, Smith JM, Orr Jr RR. Aging-dependent modification of lipid composition and lipid structural order parameter of hepatic mitochondria. Arch Biochem Biophys 1982;217:351-61.

[208] Mecocci P, Beal MF, Cecchetti R, Polidori MC, Cherubini A, Chionne F, et al. Mitochondrial membrane fluidity and oxidative damage to mitochondrial DNA in aged and AD human brain. Mol Chem Neuropathol 1997;31: 53-64.

[209] Simopoulos AP. Omega-3 fatty acids in inflammation and autoimmune diseases. J Am Coll Nutr 2002;21:495-505.

[210] Din JN, Newby DE, Flapan AD. Omega 3 fatty acids and cardiovascular disease - fishing for a natural treatment. BMJ 2004;328:30-5.

[211] Ruxton CH, Reed SC, Simpson MJ, Millington KJ. The health benefits of omega3 polyunsaturated fatty acids: a review of the evidence. J Hum Nutr Diet 2004:17:449-59.

[212] McLennan PL, Abeywardena MY, Charnock JS. The influence of age and dietary fat in an animal model of sudden cardiac death. Aust NZ J Med 1989;19:1-5.

[213] Burr ML, Gilbert JF, Holliday RM, Elwood PC, Fehily AM, Rogers S, et al. Effects of change in fat, fish, and fibre intakes on death and myocardial reinfarction: diet and reinfarction trial. Lancet 1989;334:757-61.

[214] Davis HR, Bridenstine RT, Vesselinovitch D, Wissler RW. Fish oil inhibits development of atherosclerosis in rhesus monkeys. Arterioscler Throm Vasc Biol 1987;7:441-9.

[215] Kromhout D, Bosschieter EB, de Lezenne Coulander C. The inverse relation between fish consumption and 20-year mortality from coronary heart disease. N Engl J Med 1985;312:1205-9.

[216] McLennan PL, Abeywardena MY, Charnock JS. Dietary fish oil prevents ventricular fibrillation following coronary artery occlusion and reperfusion. Am Heart J 1988;116:709-17.

[217] Weiner BH, Ockene IS, Levine PH, Cuénoud HF, Fisher M, Johnson BF, et al. Inhibition of atherosclerosis by cod-liver oil in a hyperlipidemic swine model. N Engl J Med 1986;315:841-6.

[218] Attorri L, Di Biase A, Di Benedetto R, Rigato P, Di Virgilio A, Salvati S. Micronutrient-enriched rapeseed oils reduce cardiovascular disease risk factors in rats fed a high-fat diet. Atherosclerosis 2010;213:422-8.

[219] Nguemeni C, Delplanque B, Rovère C, Simon-Rousseau N, Gandin C, Agnani G, et al. Dietary supplementation of alpha-linolenic acid in an enriched rapeseed oil diet protects from stroke. Pharmacol Res 2010;61:226-33.

[220] Caygill CP, Charlett A, Hill MJ. Fat, fish, fish oil and cancer. Br J Cancer 1996;74:159-64.

[221] Gonzalez M, Schemmel R, Dugan L, Gray J, Welsch C. Dietary fish oil inhibits human breast carcinoma growth: a function of increased lipid peroxidation. Lipids 1993;28:827-32.

[222] Kien C. Dietary interventions for metabolic syndrome: role of modifying dietary fats. Curr Diab Rep 2009;9:43-50.

[223] Spiekerkoetter U, Bastin J, Gillingham M, Morris A, Wijburg F, Wilcken B. Current issues regarding treatment of mitochondrial fatty acid oxidation disorders. J Inherit Metab Dis 2010;33:555-61.

[224] Yamaoka S, Urade R, Kito M. Cardiolipin molecular species in rat heart mitochondria are sensitive to essential fatty acid-deficient dietary lipids. J Nutr 1990;120:415-21.

[225] Aoun M, Fouret G, Michel F, Bonafos B, Ramos J, Cristol JP, et al. Dietary fatty acids modulate liver mitochondrial cardiolipin content and its fatty acid composition in rats with non alcoholic fatty liver disease. J Bioenerg Biomembr 2012;44:439-52.

[226] Frangopol PT, Mihailescu D. Interactions of some local anesthetics and alcohols with membranes. Colloids Surf B Biointerfaces 2001;22:3-22.

[227] Evers AS, Elliott WJ, Lefkowith JB, Needleman P. Manipulation of rat brain fatty acid composition alters volatile anesthetic potency. J Clin Invest 1986;77:1028-33. 
[228] Zhang J, Hadlock T, Gent A, Strichartz GR. Tetracaine-membrane interactions: effects of lipid composition and phase on drug partitioning, location, and ionization. Biophys J 2007;92:3988-4001.

[229] Barry J, Fritz M, Brender JR, Smith PES, Lee D-K, Ramamoorthy A. Determining the effects of lipophilic drugs on membrane structure by solid-state NMR spectroscopy: the case of the antioxidant curcumin. J Am Chem Soc 2009;131:4490-8.

[230] Luxo C, Jurado AS, Custódio JBA, Madeira VM. Use of Bacillus stearothermophilus as a model to study tamoxifen-membrane interactions. Toxicol Vitro 1996;10:463-71.

[231] Monteiro JP, Martins JD, Luxo PC, Jurado AS, Madeira VMC. Molecular mechanisms of the metabolite 4-hydroxytamoxifen of the anticancer drug tamoxifen: use of a model microorganism. Toxicol Vitro 2003;17:629-34.

[232] Sousa C, Nunes C, Lúcio M, Ferreira H, Lima JLFC, Tavares J, et al. Effect of nonsteroidal anti-inflammatory drugs on the cellular membrane fluidity. J Pharm Sci 2008;97:3195-206.

[233] Monteiro J, Martins A, Lúcio M, Reis S, Geraldes C, Oliveira P, et al. Interaction of carbonylcyanide p-trifluoromethoxyphenylhydrazone (FCCP) with lipid membrane systems: a biophysical approach with relevance to mitochondrial uncoupling. J Bioenerg Biomembr 2011;43:287-98.

[234] Monteiro JP, Martins AF, Lúcio M, Reis S, Pinheiro TJT, Geraldes CFGC, et al. Nimesulide interaction with membrane model systems: are membrane physical effects involved in nimesulide mitochondrial toxicity? Toxicol Vitro 2011;25:1215-23.

[235] Donato MM, Jurado AS, Antunes-Madeira MC, Madeira VMC. Bacillus stearothermophilus as a model to evaluate membrane toxicity of a lipophilic environmental pollutant (DDT). Arch Environ Contam Toxicol 1997;33:109-16.

[236] Martins JD, Monteiro JP, Antunes-Madeira MC, Jurado AS, Madeira VMC. Use of the microorganism Bacillus stearothermophilus as a model to evaluate toxicity of the lipophilic environmental pollutant endosulfan. Toxicol Vitro 2003;17:595-601.

[237] Monteiro J, Videira R, Matos M, Dinis A, Jurado A. Non-selective toxicological effects of the insect juvenile hormone analogue methoprene. A membrane biophysical approach. Appl Biochem Biotechnol 2008;150:243-57.

[238] Nunes C, Sousa C, Ferreira H, Lucio M, Lima JL, Tavares J, et al. Substituted phenols as pollutants that affect membrane fluidity. J Environ Biol 2008;29:733-8.

[239] Martins JD, Jurado AS, Moreno AJM, Madeira VMC. Comparative study of tributyltin toxicity on two bacteria of the genus Bacillus. Toxicol Vitro 2005;19:943-9.

[240] Zsigmond E, Clandinin MT. Modulation of mitochondrial ATPase sensitivity to inhibitors and stimulators by diet-induced changes in membrane lipid. Int J Biochem 1986;18:505-11.

[241] Monteiro JP, Oliveira PJ, Moreno AJM, Jurado AS. Disruption of hepatic mitochondrial bioenergetics is not a primary mechanism for the toxicity of methoprene - relevance for toxicological assessment. Chemosphere 2008;72:1347-54.

[242] Jurado AS, Fernandes M, Videira R, Peixoto F, Joaquim V. Herbicides: the face and the reverse of the coin. An in vitro approach to the toxicity of herbicides in non-target organisms. In: Kortekamp A, editor. Herbicides and environment. Vienna, Austria: INTECH; 2011.

[243] Fernandes MAS, Jurado AS, Videira RA, Santos MS, Moreno AJM, Velena A, et al. Cerebrocrast promotes the cotransport of $\mathrm{H}+$ and $\mathrm{Cl}-$ in rat liver mitochondria. Mitochondrion 2005;5:341-51.

[244] Fernandes MAS, Pereira SPS, Jurado AS, Custódio JBA, Santos MS, Moreno AJM, et al. Comparative effects of three 1,4-dihydropyridine derivatives [OSI-1210, OSI-1211 (etaftoron), and OSI-3802] on rat liver mitochondrial bioenergetics and on the physical properties of membrane lipid bilayers: relevance to the length of the alkoxyl chain in positions 3 and 5 of the DHP ring. Chem Biol Interact 2008;173:195-204.

[245] Luxo C, Jurado AS, Madeira VM. Toxicity assessment of tamoxifen by means of a bacterial model. Appl Biochem Biotechnol 2000;87:219-32.

[246] Donato MM, Jurado AS, Antunes-Madeira MC, Madeira VM. Membrane lipid composition of Bacillus stearothermophilus as affected by lipophilic environmental pollutants: an approach to membrane toxicity assessment. Arch Environ Contam Toxicol 2000;39:145-53.

[247] Pereira SP, Fernandes MA, Martins JD, Santos MS, Moreno AJ, Vicente JA, et al Toxicity assessment of the herbicide metolachlor comparative effects on bacterial and mitochondrial model systems. Toxicol Vitro 2009;23:1585-90.

[248] Escribá PV. Membrane-lipid therapy: a new approach in molecular medicine Trends Mol Med 2006:12:34-43.

[249] Lundbaek JA. Lipid bilayer-mediated regulation of ion channel function by amphiphilic drugs. J Gen Physiol 2008;131:421-9.

[250] Andersen OS, Koeppe RE. Bilayer thickness and membrane protein function: an energetic perspective. Annu Rev Biophys Biomol Struct 2007;36:107-30.

[251] Lundbaek JA, Birn P, Girshman J, Hansen AJ, Andersen OS. Membrane stiffness and channel function. Biochemisty 1996;35:3825-30.

[252] Lundbaek JA, Birn P, Hansen AJ, Sogaard R, Nielsen C, Girshman J, et al Regulation of sodium channel function by bilayer elasticity. J Gen Physio 2004;123:599-621.

[253] Szabo G, Dolganiuc A, Dai Q, Pruett SB. TLR4, ethanol, and lipid rafts: a new mechanism of ethanol action with implications for other receptor-mediated effects. J Immunol 2007;178:1243-9.

[254] Paradies G, Petrosillo G, Paradies V, Reiter RJ, Ruggiero FM. Melatonin cardiolipin and mitochondrial bioenergetics in health and disease. J Pineal Res 2010;48:297-310.

[255] Pepe S, Tsuchiya N, Lakatta EG, Hansford RG. PUFA and aging modulate cardiac mitochondrial membrane lipid composition and $\mathrm{Ca}^{2+}$ activation of PDH. Am J Physiol 1999;276:H149-58.

[256] Ardail D, Privat JP, Egretcharlier M, Levrat C, Lerme F, Louisot P. Mitochondrial contact sites - lipid-composition and dynamics. J Biol Chem 1990;265:18797-802. 